\title{
Die Besitznahme der Oberrheinlande durch Rom - Aspekte einer Bevölkerungs- und Militärgeschichte*
}

\author{
Rainer Wiegels
}

\section{Methodische Vorüberlegungen}

Römer, Kelten und Germanen haben ihren festen Platz in der historischen Erinnerung. Dies betrifft nicht nur epochale Vorgänge und Ereignisse von weitreichender, gleichsam weltgeschichtlicher Bedeutung, sondern auch solche von begrenzter zeitlicher wie räumlicher Relevanz. Letzteres gilt auch für das Gebiet von Hoch- und Oberrhein mit einer eigenen Geschichte, die selbstverständlich ihrerseits zugleich in übergreifende historische Prozesse eingebettet ist. Im Folgenden wollen wir uns eingehender nur mit der frühen Phase der Begegnung zwischen Römern und jenen Völkerschaften befassen, die gemeinhin den Kelten bzw. den Germanen zugeordnet werden, und einige wichtige Aspekte der Bevölkerungsgeschichte der Oberrheinlande am Übergang von der Latènezeit zur römischen Epoche thematisieren. Mit dieser eng verbunden ist die römische Heeresgeschichte, der wir für die Zeit von Caesars Feldzug in Gallien bis zum Ende der iulisch-claudischen Dynastie wenigstens in einigen Grundzügen nachgehen wollen. Die unter ganz anderen historischen Bedingungen erfolgten Angriffe mit der folgenden Landnahme der Alamannen und Franken ab dem 3. Jahrhundert n. Chr. blenden wir aus; dies wäre Gegenstand einer eigenen Analyse. Trotz bemerkenswerter Fortschritte der jüngeren Vergangenheit ist allerdings nicht zu übersehen, dass nach wie vor eines der Hauptprobleme der modernen Forschung zur frühen Geschichte des hier im Zentrum des Interesses stehenden Raumes im sachgerechten Verständnis des Übergangs von der protohistorischen zur römischen Epoche besteht. ${ }^{1}$ Jedoch scheint zumindest darin weitgehend Konsens zu bestehen, dass - wie Lars Blöck in seiner jüngst publizierten, detailreichen Dissertation zur Besiedlung des südlichen Oberrheingebietes vermerkt. - „,der Übergang von der Spätlatène- zur römischen Zeit innerhalb der Besiedlungsgeschichte [---] einen tiefgreifenden Einschnitt darstellt.“2

Im Allgemeinen prägen eher diffuse Vorstellungen als präzises Wissen die Erinnerung an die historischen Vorgänge in der Frühphase der Landnahme durch die Römer, was aber kaum verwundert. Zwar hat die Geschichte der Oberrheinlande unter

\footnotetext{
* Der Beitrag beruht im Wesentlichen auf einem Vortrag, den ich im Mai 2017 auf Einladung des Faches Alte Geschichte an der Universität Graz gehalten habe. Daher bleibt der Charakter eines Vortrags-Textes weitgehend unverändert; Anmerkungen sind auf das Nötigste beschränkt. Der Quellenlage entsprechend nimmt der erste Teil der Ausführungen durchweg unmittelbaren Bezug auf die literarischen Zeugnisse, der zweite Teil dagegen basiert zwangsläufig in erster Linie auf den Forschungsergebnissen in der Sekundärliteratur, wobei auf eine umfassende Erörterung mancher Detailprobleme und Kontroversen verzichtet werden muss. Wichtige Literatur enthält die beigefügte Auswahlbibliographie. Im Übrigen s. das umfassende Quellen- und Literaturverzeichnis zur römerzeitlichen Besiedlung im rechten südlichen Oberrheingebiet bei BLÖCK 2016, 471-510.

${ }^{1}$ REDDÉ 2009, 406.

${ }^{2}$ BLÖCK 2016, 223 im Rahmen seiner archäologisch-historischen Auswertung: „Von der Spätlatènezeit bis zu den augusteischen Eroberungskriegen in Germanien“ (S. 223-227). - Einen nützlichen Ausgangspunkt für aktuelle Forschungen bietet ASSKAMP 1989. Vgl. auch den zusammenfassenden Überblick über die Situation im letzten vorchristlichen Jahrhundert in Südwestdeutschland von Fischer 1988. Einen weitgespannten Abriss zu Gallien bietet FERDIÈRE 2005.
} 
Einschluss der anrainenden Gebiete des Hochrheins in der Zeit etwa vom ersten vorchristlichen bis nach der Mitte des ersten nachchristlichen Jahrhunderts die historische Forschung seit mehr als zweihundert Jahren beschäftigt, dennoch kann aber keine Rede davon sein, dass sich der Nebel von Meinungen und Hypothesen allenthalben gelichtet hätte. Der Grund hierfür liegt vor allem darin, dass wir nur hin und wieder über gesicherte, dann aber meist nur punktuelle Anhaltspunkte verfügen, die zur Klärung der verschiedenen weitreichenden Probleme beitragen. Nur gelegentlich ermöglichen Kombination und zusammenfassende Deutung von Einzelbeobachtungen eine solide Rekonstruktion der historischen Prozesse, und umso größer ist die Versuchung, aus diesen für sich schon in vielen Fällen nicht unumstrittenen Bausteinen ein Gesamtgebäude zu errichten, das zwar auf schwachen Fundamenten steht, aber der Eigenart dieses Fundamentes entsprechend auch nicht von selber einzustürzen pflegt. Es bedarf dann in der Regel eines Anstoßes von außen, um die Schwachstellen und mangelnde Tragfähigkeit des verwendeten Materials aufzudecken. Solches geschieht nicht selten durch Aufschlüsse, welche der Spaten zutage fördert, wodurch sich neue, gelegentlich auch überraschende Zusammenhänge abzeichnen. Sie stellen wiederholt manche bislang als gesichert geltende Erkenntnisse in Frage oder lassen diese in einem ganz anderen Licht als zuvor erscheinen.

Bei dieser Sachlage kommt erschwerend hinzu, dass die Bausteine als solche von ganz unterschiedlicher Beschaffenheit sind. Neben der in ihrer Substanz seit der Frühen Neuzeit unveränderten literarischen Überlieferung sowie der Auslegung von Personen-, Orts- und Völkernamen sind es eben vor allem die sich beständig vermehrenden archäologischen Funde und Befunde, dazu Münzen und Inschriften, welche zur Rekonstruktion der geschichtlichen Vergangenheit herangezogen werden. Alle diese Quellentypen sind Gegenstand von eigenen Forschungsdisziplinen mit speziellen methodischen Verfahren der Interpretation, besitzen aber auch entsprechende Grenzen, was die aus ihnen zu gewinnenden Aufschlüsse betrifft. Man ist jedenfalls gut beraten, vor vorschnellen Verallgemeinerungen den Quellenwert jedes einzelnen Zeugnisses im Kontext seiner eigenen Voraussetzungen kritisch zu prüfen, bevor eine Synthese gewagt werden kann, wobei Letzteres angesichts der zunehmenden Spezialisierung der wissenschaftlichen Disziplinen ein durchaus risikoreiches Unterfangen ist. Geschichtliche Prozesse spiegeln sich in den verschiedenen Quellengattungen auf unterschiedliche Weise wider, und nicht übersehen werden darf auch die Abhängigkeit einer jeden Rekonstruktion von Grundeinstellungen und Perspektiven der modernen Interpreten. Nur im Idealfall lassen sich wie in einem Puzzle alle Elemente zu einem einheitlichen Bild zusammenfügen, wobei ein vollständiges Gelingen kaum zu erwarten ist. Bei dieser Sachlage ist jedenfalls im Zweifelsfall das Offenhalten von Fragen wissenschaftlichem Fortschritt förderlicher als Versuche gewaltsamer Harmonisierung.

Grundsätzlich ist es unumgänglich, sich zunächst auf bestimmte Aspekte eines facettenreichen Problemkomplexes zu beschränken, um nicht im Generellen, das zur Banalität neigt, das Charakteristische und Besondere aus dem Auge zu verlieren. Wenn wir unter diesen Voraussetzungen dennoch hier einen gewissen Überblick vermitteln wollen, so kann dieser weder endgültig verbindlich noch in jeder Hinsicht vollständig sein. Grundlegend für eine historische Analyse ist zunächst die kritische Auswertung der literarischen Überlieferung, welche zwar nur aus griechischer bzw. römischer Feder vorliegt und demnach perspektivische Deutungen aus einer Außensicht vermittelt, dennoch aber den unverzichtbaren sachlichen Rahmen für alle weitergehenden Folgerungen bietet, die etwa aus archäologischen Funden und Befunden oder Inschriften gezogen werden können. Allerdings vermögen Letztere durchaus in mancher Hinsicht einzigartige Aufschlüsse zu Ereignissen und strukturellen Zusammenhängen zu liefern. 


\section{Zur Bevölkerungsgeschichte der Oberrheinlande im Spiegel der literarischen Quellen}

\section{a. Grundprobleme der literarischen Überlieferung}

Bereits ein flüchtiger Blick auf die erhaltene literarische Überlieferung zu unserem Fragekomplex führt zu der Erkenntnis, dass diese nicht durchgängig und in jeder Hinsicht tauglich ist, so dass die Informationen nicht ohne weiteres kritiklos übernommen werden können. Ein schlagendes Beispiel hierfür liefert das geographische Werk des Klaudios Ptolemaios, das dieser um 140 n. Chr. abgefasst hat. Es enthält Angaben zur Lokalisierung von Orten, Stämmen und Flüssen unter anderem auch in der Gallia Belgica, Germania und Raetia. Seit langem bemüht sich die Forschung, die Angaben bei Ptolemaios auf moderne Landkarten zu übertragen, allerdings nicht immer mit überzeugendem Erfolg. Die Arbeitsweise des Gelehrten sowie Ordnung und Überlieferung des Materials werfen bis heute erhebliche Probleme auf. Zwar wurden 2011 in der Zeitschrift „Germania“ die Ergebnisse eines von der DFG geförderten Forschungsprojektes an der TU Berlin zu „Welt des Ptolemaios“ und „Antiker Atlas des Ptolemaios“ bei spezieller Berücksichtigung der ca. 90 Ortsangaben im Gebiet der Germania magna vorgelegt, jedoch stießen die Identifizierungen auch auf Skepsis. ${ }^{3}$ Jedenfalls weist die Lokalisierung und Zuordnung von Orten entlang des Rheins bei Ptolemaios (2,9,8 f.) so viele Fehler und Irrtümer auf, dass Vorsicht angebracht ist bei der Übernahme aller Angaben, die anderweitig nicht abgesichert oder wenigstens wahrscheinlich gemacht werden können. ${ }^{4}$ Wenn Ptolemaios die colonia Ulpia Traiana/Xanten als angeblichen Standort der tatsächlich in Mogontíacum/Mainz stationierten legio XXII verzeichnet und mit Positionsangaben südlich von Bonna/Bonn versieht, Mogontíacum selber dagegen nördlich des die Provinzen Germania superior und inferior trennenden Obrinkas/Vinxtbaches lokalisiert, und wenn er des weiteren Borbetomagus/Worms fälschlich südlich von Noviomagus/Speyer und Breucomagus/Brumath südlich statt nördlich von Argentorate/Straßburg ansetzt, das zudem irrtümlich in das Gebiet der Vangionen statt der Triboker verlegt wird, dann ist grundsätzlich ein gewisses Misstrauen gegenüber allen anderweitig nicht zu kontrollierenden Lokalisierungen angebracht. ${ }^{5}$ Während aber die Lokalisierung von Argentorate bei Ptolemaios allenthalben als Fehler betrachtet wird, nimmt man die nach der colonia Augusta Raurica/Augst folgende von Argentovaria (früher Horbourg, jetzt vielleicht eher Oedenburg) im Gebiet der Rauriker als gesichert und keines Beweises bedürftig an. ${ }^{6}$ Jedoch fehlt es bislang nicht nur an bestätigenden Zeugnissen, sondern in jedem Fall ist die generelle Abfolge der Orte von Norden nach Süden an dieser Stelle des Textes gedreht. Selbstverständlich müssen sich das Stammesgebiet und die civitas der Rauriker im Umfeld von Helvetiern, Sequanern und Tribokern erstreckt haben, zumal die colonia Augusta Raurica einen deutlichen Fingerzeig liefert (Abb. 1).

\footnotetext{
${ }^{3}$ NÜSSE/MARX/LELGEMANN 2011.

${ }^{4}$ Kritisch dazu schon NeSSELHAUF 1951, $72 \mathrm{f}$.

${ }_{5}^{5}$ Auf verschiedene Versuche der neuzeitlichen Forschung, die Arbeitsweise des Geographen und die Fehler zu erklären, brauchen wir an dieser Stelle nicht weiter einzugehen. Wie gesehen, lassen sich aber manche Irrtümer leicht aufgrund anderer Zeugnisse korrigieren.

${ }^{6}$ Die Forschung konnte herausarbeiten, dass Ptolemaios offenbar die Stammesnamen erst nach Lokalisierung der Ortsnamen in seine Listen eingefügt hat, was bei kritischer Würdigung zu berücksichtigen ist.
} 
An der Wende vom 1. zum 2. Jh. veröffentlichte P. Cornelius Tacitus seine berühmte Schrift De origine et situ Germaniae, wie sie seit der frühen Neuzeit überschrieben wird, zu übersetzen etwa mit „Germanische Urgeschichte und Landeskunde“, kurz: seine Germania. Der Eingangssatz lautet wie folgt: Germanien in seinem ganzen Umfang wird von den Galliern sowie von den Raetern und Pannoniern durch die Flüsse Rhein und Donau, von den Sarmaten und Dakern durch gegenseitige Furcht oder durch Gebirgszüge geschieden. Die Formulierung ist auf den ersten Blick merkwürdig. Seit Jahrzehnten und vollends seit der formellen Einrichtung der Provinz Germania superior sowie der Anlage des Limes oder zumindest einer Reihe von Kastellen in dessen Vorfeld an der Wende vom 1. zum 2. Jahrhundert bildeten nicht mehr der Rhein vom Süden bis in die Nähe von Koblenz und auch nicht mehr die Donau bis fast Regensburg die Grenze zum Gebiet der Germania magna. Unabhängig aber von den realen Verhältnissen war die geographische und ethnische Grenzziehung an Rhein und Donau im Bewusstsein der Römer und damit auch in der vor allem für das stadtrömische Lesepublikum bestimmten Geschichtsschreibung zu einem Topos geworden, welcher fortwirkte und letztlich auf Caesar zurückgeht. Dieser hatte in seiner Schrift über den Gallischen Krieg den Rhein nicht ohne gewisse Willkür und durchaus im Wissen um die damit verbundenen Ungenauigkeiten aus machtpolitischen, aber auch pragmatischen Erwägungen zur Grenze zwischen keltisch-gallischer, d.h. in seinem Urteil zivilisierter, und germanischer, d.h. wilder und kriegerischer Bevölkerung erklärt. Eine solche ethnische Trennlinie musste für die römische Öffentlichkeit mit ihrer Vorliebe für klare und markante Flussgrenzen besonders einleuchtend sein. Sie wurde seit Caesar offenbar allenthalben rezipiert, wie unter anderem ein Fragment in Sallusts Historien belegt. ${ }^{7}$ Wenn wir also den Blick zurück auf die Oberrheinlande richten, werden wir zwangsläufig zunächst auf Caesar verwiesen. Nachrichten aus späterer Zeit stehen - soweit wir sie kennen - durchweg in mehr oder weniger direkter caesarischer Tradition.

Aber hier werden wir sogleich mit einem weiteren Problem konfrontiert. In antikem Urteil galt Caesar zwar nicht unbedingt als großer Staatsmann, wohl aber als bedeutender Heerführer und erstrangiger Stilist, was seine eigenhändig verfassten Schriften betrifft. Mit Recht wird warnend vermerkt, dass man sich nicht ,durch die betonte Sachlichkeit und vielgerühmte Präzision des caesarischen Berichts darüber täuschen lassen [darf], dass er von einer Person [sc. eben Caesar] stammt, der in einem politischen Hochspannungsfeld stehend sich an ein Publikum wendet, dem er nicht darlegt, wie die Dinge waren, sondern wie er will, dass sie aufgefasst werden. ${ }^{68}$ Wenn man sich dieses nicht klar macht, versperrt man sich den Weg zur Rekonstruktion geschichtlicher Zusammenhänge. Dieses gilt auch für scheinbar politisch so belanglose Fragen wie die Besiedlungsverhältnisse der Oberrheinlande. Hinzu kommt das Problem der sachlichen Einordnung der ethnographischen Exkurse in Caesars De bello Gallico. Deren caesarische Urheberschaft wird von der Forschung in einigen Fällen mit guten Gründen ebenso angezweifelt wie die Zeitstellung derselben und damit auch der in diesen berichteten Zustände, ob vor- oder nachcaesarisch. Trotz Lücken und problematischer Autorenschaft vermitteln sie dennoch grundlegende Informationen über die Bevölkerungsgeschichte des uns hier interessierenden Raumes aus der Frühzeit der Besitznahme durch die Römer. Dieses gilt besonders für den Exkurs im vierten Buch im Rahmen der Berichte zum Jahr 55 v. Chr., wo die Stämme entlang des Verlaufs des Rheins von seiner Quelle ausgehend aufgelistet werden (B. G. 4,10). Wir lesen dort: Der Rhein entspringt im Gebiet der Lepontier, eines Alpenstammes, und fließt reißend in einer

\footnotetext{
${ }^{7}$ Sall., hist. 1 fr. 11 (Maurenbrecher): Unterwerfung ganz Galliens diesseits des Rheins 51 v. Chr.

${ }^{8}$ NeSSELHAUf $1951,75$.
} 
langen Strecke durch das Gebiet der Nemeter, Helvetier, Sequaner, Mediomatriker, Triboker und Treverer und teilt sich in Meeresnähe in mehrere Arme [---]. Wie unschwer zu erkennen, ist die Reihenfolge der Stämme von Süd nach Nord völlig durcheinandergeraten, Stämme nördlich der Treverer werden in diesem Zusammenhang gar nicht erwähnt. Über allgemeine Vorstellungen hinaus lässt sich also ohne vergleichende Kritik den Aussagen nur wenig entnehmen.

Nicht unproblematisch sind auch die Angaben bei Strabo, der unter Augustus sein geographisches Werk mit manchen historischen Notizen verfasst und bald nach dessen Tod abgeschlossen hatte. Er berichtet in seinem vierten Buch (4,3,3-5 = 192194 C) über die linksrheinischen sowie im siebten Buch (7,1,2-5 = 290-292 C) über die rechtsrheinischen Siedlungsverhältnisse in augusteischer Zeit, soweit ihm diese bekannt waren. Dabei dienten ihm Informationen aus früherer, nicht zuletzt caesarischer Zeit als Grundlage, was er aber nicht immer ausdrücklich vermerkt, welche dann von ihm durch aktuelle Erkenntnisse aufgrund von Veränderungen der folgenden rund 60 Jahre ergänzt werden. Dies gilt naturgemäß vor allem für die Verhältnisse im Bereich der Germania im engeren Sinn. Vollständigkeit wird man nicht von einem Autor erwarten dürfen, der selber zu seinen Prinzipien der Berichterstattung vermerkt $(4,1,1=$ 176 C): Alles, was durch die Natur und durch die Völker geschieden ist, muss der Erdbeschreiber darstellen, wenn es nämlich der Erwähnung wert ist; alles aber, was die Herrscher, die den Staat nach den Zeitumständen verwalten, mannigfach umgestalten, das genügt nur in allgemeinen Umrissen anzugeben, indem man die genauere Darstellung anderen überlässt.

Bei dieser Gemengelage ist jedenfalls Zurückhaltung vor allzu schnellen Schlussfolgerungen angebracht und die literarische Überlieferung zu überfordern in dem Bemühen, aus ihr Informationen herauszupressen, die zu liefern sie weder imstande noch willens ist.

Noch an der Schwelle vom 2. zum 1. vorchristlichen Jahrhundert hatte man jedenfalls in Rom kaum Kenntnisse von den Verhältnissen in Mitteleuropa. Daran hatten zunächst auch die seit dem frühen 2. Jahrhundert v. Chr. vor allem von Aquileia im Norden der Adria ausgehenden, dann über die östlichen Alpen und das Königreich $\mathrm{No}$ ricum in den mitteleuropäischen Raum reichenden Handelskontakte nichts Entscheidendes geändert und ebenso wenig entsprechende, von Südfrankreich (Massilia) aus bis tief nach Gallien reichende Verbindungen, die auch den Oberrhein berührt hatten. Nach endgültiger Sicherung der auch schon zuvor gelegentlich genutzten Alpenpässe durch Rom 15 v. Chr. entwickelte sich von Norditalien aus auf breiter Front unmittelbar über die Alpen hinweg ein reger Verkehr mit der nördlichen Voralpenzone mit Fortsetzung und Intensivierung nach Norden über den Ober- und Hochrhein (Abb. 2).

Griechischen Vorstellungen folgend teilte man die in Mitteleuropa wohnende Bevölkerung in Kelten und Skythen. Gruppen, die weder der einen noch der anderen Großethnie eindeutig zuzuordnen waren, wurden kurzerhand als Kelto-Skythen registriert. Zu ihnen gehörten irgendwie die Kimbern, die erst sekundär den Germanen zugerechnet wurden. Deren Zug in den östlichen Raum der Alpen und von dort nach Gallien mit Bedrohung Oberitaliens gegen Ende des 2. Jahrhunderts v. Chr. war Teil eines umfänglichen Gärungsprozesses, in dessen Folge die Bevölkerung Mitteleuropas lawinenartig in Bewegung geraten war, was auch in Rom nicht unbemerkt bleiben konnte. Bereits eine Generation später wusste man jedenfalls in Rom, Kelten und Germanen zu unterscheiden, wie eine Bemerkung Ciceros aus dem Jahr 56 v. Chr. belegt (de prov. cons. 13,33). Auch in der Überlieferung zu den Sklavenkriegen 73-71 v. Chr. ist die Rede von ethnischen Gruppierungen der Thraker, Kelten und Germanen, ethnischen Großverbänden, die auch Caesar wie selbstverständlich gegenüberstellt. Wir können 
und wollen an dieser Stelle nicht auf das viel diskutierte Problem des Aufkommens des Germanennamens eingehen. Jedoch wird man mit einiger Zuversicht sagen können, dass bei dem Prozess zwischen Selbstzuordnung und Fremdbenennung der Germanen Caesar zwar nicht der erste und also auch nicht der Urheber war, wohl aber derjenige, der die Zweiteilung zwischen Kelten und Gallier auf der einen und Germanen auf der anderen Seite festgeschrieben und im allgemeinen Bewusstsein der Zeitgenossen verankert hat. ${ }^{9}$ Bestimmte Vorgänge an der Peripherie des Herrschaftsgebietes der Römer, welches damals bis an den Genfer See reichte, weckten zwar ein gewisses Interesse in Rom, entscheidend wurde allerdings, was Caesar daraus gemacht hat. Mit ihm setzt darum auch erst die eigentliche Überlieferung zur Geschichte der Oberrheinlande zur Zeit der römischen Besitznahme ein.

\section{b. Das Zeugnis der literarischen Quellen}

Gleich zu Beginn seines Werkes hebt Caesar hervor, dass der Rhein die Helvetier von den Germanen trenne (B. G. 1,2,3). ${ }^{10}$ Damit muss der Hochrhein bis zum Bodensee gemeint sein, da der Jura im Westen die Grenze zwischen Helvetiern und Sequanern markierte (s. auch B. G. 1,8,1 oder Strabo 4,3,4=193 C) und am Oberrhein der Schwarzwald eine durchzugsfeindliche Barriere bildete. Auch an anderer Stelle unterstreicht Caesar die Bedeutung des Rheins als Grenze zu den Germanen, wenn er etwa die Helvetier zwingt, in ihre Heimat zurückzukehren, damit nicht Germanen qui trans Rhenum incolunt linksrheinisches Gebiet besetzen (B. G. 1,28,4). Ebenso gilt für Strabo unbeschadet fehlerhafter Vorstellungen über die Verläufe wichtiger Flüsse in Gallien der Rhein als Grenze des Helvetiergebietes zu den Germanen (Strabo 4,3,3 f. $=192 \mathrm{f}$. C; vgl. 7,1 f. $=289$ f. C).

Sehr wahrscheinlich erfolgten die Abwanderung der Helvetier aus Südwestdeutschland auf Druck der Germanen und die Besitznahme der Ländereien vor allem im Bereich der heutigen Schweiz nicht allzu lange vor der caesarischen Zeit. Auch ohne konkrete Zeugnisse ist anzunehmen, dass dieser Vorgang irgendwie im Zusammenhang stand mit den umfassenden Bevölkerungsbewegungen im großgermanischen Raum, die auch die Züge von Kimbern und Teutonen auslösten. Einer Mitteilung des Tacitus in seiner Germania (28) zufolge saßen die Helvetier einst zwischen Main, Rhein u. Hercynischem Wald. Ihnen benachbart waren die Boier, von denen sich ein Teil den Helvetiern angeschlossen hatte, wie Caesar berichtet (B. G. 1,5,4; vgl. auch Strabo 7,2,1= 293 C über die früheren Sitze der Boier im Hercynischen Wald). ${ }^{11}$ Als Caesar die Provinz Gallien zur Verwaltung übernahm, suchten die Helvetier erneut durch Abwanderung diesem offenbar weiter bestehenden Druck auszuweichen, der sich auch in den Unternehmungen des Ariovist am südlichen Oberrhein und im etwa gleichzeitigen Vorstoß von Sueben gegen die Treverer (Caes. B. G. 1,37,3) im Bereich des Mittelrheins dokumentiert. Caesar bot dies den willkommenen Anlass einzugreifen, um seine persönlichen politischen Ambitionen zu befördern. Dabei wird er nicht müde bei dem Versuch, die römische Öffentlichkeit von der großen Gefahr zu überzeugen, welche von einem Auszug der Helvetier nach Gallien unter Zurücklassung einer Landschaft, welche germanischer Besitznahme offen stehen würde, ausgehe. Bei genauerer Analyse

\footnotetext{
${ }^{9}$ Vgl. dazu eingehend TIMPE 1998, 2-13.

${ }^{10}$ Zum Krieg Roms gegen die Helvetier s. WALSER 1998. - Zu Caesar und Germanen s. WALSER 1956 als Ausgangspunkt.

${ }^{11}$ Bemerkenswert ist in diesem Zusammenhang auch der Nachweis eines numerus exploratorum Tribocorum et Boiorum am Limes im 2. Jahrhundert n. Chr.; gewöhnlich werden derartige militärische Formationen von benachbarten Bevölkerungsgruppen gebildet, vgl. dazu WIEGELS 1981.
} 
wird aber deutlich, dass die Helvetier auf Siedlungsland aus waren und jedenfalls nicht in erster Linie auf Beutezug oder gar großräumige Herrschaftsbildung, wobei sich verschiedene Intentionen auch nicht gegenseitig ausschließen. Jedoch eben dieses Motiv einer Herrschaftsbildung, verbunden mit einem unbändigen Ehrgeiz ihres Führers, unterstellt Caesar den Helvetiern (B. G. 1,1,3; 1, 2), und es lässt sich leicht zeigen, warum. Denn sein brutales Vorgehen aus eigensüchtigen Motiven sollte und musste vor der misstrauischen römischen Öffentlichkeit und dem Senat gerechtfertigt werden. Um daher ein Festsetzen von Germanen auf der linken Rheinseite zu vermeiden, schickte Caesar die 58 v. Chr. bei Bibracte besiegten Helvetier sowie Tulinger, Latobiker und wohl auch Rauriker, welche dem auszugswilligen Verband angehörten, nach deren deditio wieder in ihre alten Sitze in der Schweiz zurück (B. G. 1,27; 1,28,4; 1,29; vgl. Plut. Caes. 18,5 f.; Dio 38,33,5 f.). ${ }^{12}$ Gruppen von Stammesangehörigen versuchten allerdings, über den Rhein in ihre alte Heimat in Südwestdeutschland zu gelangen (Dio 38,33,6 - wohl auf Livius und Asinius Pollio zurückgehend; vgl. Caes. B. G. 1,27,4), eben jenes Gebiet, welches später Ptolemaios als von den Helvetiern verlassenes Land bzw. als Einöde bezeichnet (Ptol. 2,11,6). Die bei Caesar überlieferte Zahl von 263.000 wanderwilligen Helvetiern und deren Verbündeten beruht zwar offenbar auf einer fehlerhaften Überlieferung und ist nach einer plausibleren Angabe bei Orosius (adv. pag. $6,7,5) \mathrm{um}$ mehr als $100.000 \mathrm{zu}$ hoch angesetzt, aber die Gliederung der Helvetier in Teilverbände wird man nicht bezweifeln können. Allerdings lassen sich diese nicht im archäologischen Fundgut oder aufgrund anderer Quellen fassen. Andererseits ist eine stammesmäßige Organisation nicht zwingend für die Bevölkerung des gesamten Oberrheingebietes vorauszusetzen.

Als dann zeitlich etwa parallel auf Initiative und unter Führung des Ariovist der Vorstoß germanischer, d. h. swebischer Scharen mit Frauen und Kindern über den Oberrhein erfolgte, griff Caesar unverzüglich an. Angeblich war er von den Häduern gebeten worden, die darauf verwiesen, dass bereits 120.000 Germanen mit ihren Familien links des Rheins stehen würden, nachdem zuvor schon 15.000 Germanen mit Ariovist als Helfer im Krieg der Averner und Sequaner gegen die Häduer den Rhein überschritten und im Gegenzug dafür Siedlungsland erhalten hätten. Dies war Ende der 70er Jahre erfolgt (Caes. B. G. 1,36,7). Jetzt seien weitere 24.000 Haruden zu ihm gestoßen, und weiterer Zuzug drohe, so dass nun die Errichtung einer eigenen, germanischen Herrschaft drohe (Caes. B. G. 1,31,5.10 in Verbindung mit 1,36,7; 1,44,13). Die Zahl legt Caesar dem Anführer der Häduer, Diviciacus, in den Mund und ist wie die anderen kaum zu kontrollieren. Auf diese Weise wird aber ein Bedrohungsszenario errichtet, welches vor allem das römische Publikum beeindrucken sollte. Zur gleichen Zeit sollen sich nach Mitteilung der Treverer 100 Stammesgruppen der Sueben am Rhein niedergelassen haben in der Absicht, den Fluss zu überschreiten (Caes. B. G. 1,37,3). Zweifellos übertreibt Caesar, wenn er den Führer einer offenbar kurzfristig zusammengesetzten Gefolgschaft als rex Germanorum bezeichnet oder auch so von den gallischen Gegnern titulieren lässt (vgl. B. G. 1,31,10 f.; 51,2; 6,12,2). Allerdings war Ariovist auch in Rom in Caesars Konsulatsjahr 59 v. Chr. vom Senat offiziell als rex et amicus

\footnotetext{
${ }^{12}$ Dass in diesem Zusammenhang weder Caesar noch später Strabo die Rauriker unter den zurück geschickten Verbänden erwähnt, hat man verschieden zu erklären versucht. Entweder vermutet man ein Versehen Caesars bzw. eine Text-lücke aufgrund des Fehlers eines mittelalterlichen Kopisten oder aber auch die Unterstellung der Rauriker unter die Sequaner zur damaligen Zeit, die demnach nicht selbständig gewesen wären, vgl. dazu Caes., B. G. 12,4 und 12,6: Wegnahme der Klienten der Sequaner nach Caesars Sieg. S. dazu bes. FISCHER 2006, 57 f. Er verweist dabei auch auf eine cohors Sequanorum et Rauricorum aus dem 2. Jahrhundert am Limes. Sicher entscheiden lässt sich die Frage beim derzeitigen Stand unseres Wissens nicht. Die grundlegenden Absichten, die Caesar mit dem Verweis der Helvetier und deren Verbündete aus Gallien im engeren Sinne verband, bleiben davon unberührt.
} 
populi Romani geehrt und anerkannt worden (Caes. B. G. 1,35,2; 1,43,4), jedoch gilt dies auch für andere Stammesführer in Gallien. ${ }^{13}$ Der Zug des Ariovist als solcher ist ebenso wenig eindeutig zu rekonstruieren wie des Näheren die Gegend, wo die Scharen am Hoch- bzw. Oberrhein über den Fluss setzten. Caesar siegte bekanntlich 58 v. Chr. in der entscheidenden Schlacht bei Mulhouse im Elsass. Der aus Angehörigen verschiedener Stämme zusammengesetzte Verband Ariovists wurde weitgehend vernichtet, sofern es den Germanen nicht gelang, über den Rhein zu entkommen (B. G. 1,53; vgl. Liv. per. 104). Nach eigenem Bekunden Caesars seien die Germanen aus Gallien herausgeworfen worden (B. G. 3,7,1: Germanis expulsis; vgl. auch Dio 38,50,4 f.; Plut. Caes. 19,11 f.). Erneut wird dem Leser seiner Berichte in Rom die bedrohliche Germanengefahr drastisch vor Augen geführt und zugleich die große Bedeutung seines diesbezüglichen Erfolgs für die Sicherheit Roms, Italiens und der gallischen Provinzen betont. Eine Folge des rigiden Vorgehens Caesars ist darin zu sehen, dass aus Südwestdeutschland jegliches gesicherte archäologische Zeugnis der germanischen Wanderscharen der Zeit Ariovists fehlt. Nicht von ungefähr drängten in den folgenden Jahren die Germanen vor allem an Mittel- und Niederrhein gegen die Rheinfront, nicht selten ihrerseits durch Vorgänge im Osten in Bewegung gesetzt, ohne dass von einem koordinierten und umfassenden Vorgehen die Rede sein kann. Dementsprechend gingen die späteren Kriegszüge der Römer gegen Germanien von dort aus, dann auch von der mittleren Donau. Der Ober- und Hochrhein dagegen blieb davon weitgehend verschont. Die beiden Rheinübergänge Caesars 55 und 53 v. Chr., welche eine Demonstration römischer Stärke waren und zugleich den Willen einer effektiven Kontrolle des rechtsrheinischen Vorfeldes als eines Glacis vor Gallien drastisch vor Augen führen sollten, fanden daher auch am Mittelrhein - etwa bei Neuwied - statt. ${ }^{14}$

Auf Grund dieser konsequent von Caesar befolgten Politik gegen die Germanen ist es ganz unwahrscheinlich, dass es Caesar war, der die germanischen Triboker, Nemeter und Vangionen in der Gefolgschaft Ariovists auf der linken Rheinseite angesiedelt oder dieses geduldet hat. Entsprechende Angaben in dem bereits zitierten caesarischen Exkurs (B. G. 4,10) können folglich nicht aus seiner Feder stammen oder auch nur zeitgenössisch sein, und auch die Mitteilung, dass diese Stämme dem Heer Ariovists angehörten (Caes. B. G. 1,51,2), ist vielleicht eine Glosse aus späterer Zeit, was andererseits jedoch auch nicht zwingend ist. Strabo bestätigt zwar, dass die Triboker im Elsass um Straßburg über den Rhein gekommen und sich im Gebiet der Mediomatriker niedergelassen hätten, nennt aber nicht Nemeter und Vangionen. Vielleicht sind diese erst später übergesiedelt, was allerdings in jedem Fall vor Mitte des 1. nachchristlichen Jahrhunderts geschehen sein muss, da sie dann als Angehörige des Imperiums reguläre Auxiliarverbände stellten. Entsprechend werden sie bei Plinius (n. h. 4,106) als linksrheinische Stämme gelistet, und die historische Wahrscheinlichkeit spricht dafür, dass alle Maßnahmen in augusteischer Zeit oder allenfalls kurz danach erfolgten. Bekannt ist, dass Agrippa die Ubier 38 oder 19 v. Chr. auf der linken Rheinseite ansiedelte, ut arcerent, non ut custodirentur, wie Tacitus vermerkt (Germ. 28,4), und dass Tiberius die Sugambrer 8 v. Chr. ebenfalls auf das linke Rheinufer überführte. Es handelt sich also um eine deutliche Kehrtwende in der Politik Roms gegenüber germanischen Stämmen in augusteischer Zeit, die auch im Donauraum Anwendung fand und

\footnotetext{
${ }^{13}$ In der Titulierung seitens Roms fehlt aber ein der pauschalisierenden Benennung des Herrschaftsbereichs als rex Germanorum entsprechender Zusatz.

${ }^{14}$ Der erste Rheinübergang wird von Caesar ausführlich geschildert und zugleich die technische Leistung hervorgehoben, vgl. Caes., B. G. 4,16-19; dazu Liv., per. 105; Suet., Caes. 25,2; Plut., Caes. 22,6-23,1; Eutrop. 6,17,3; Flor. 1,45.14; Oros., adv. pag. 6,9,1. - Der zweite Rheinübergang s. Caes., B. G. 6,9 f.; 6,29; vgl. Liv., per. 107; Flor. 1,45,15.
} 
als Maßnahme zur Entlastung von feindlichem Druck fortan ebenfalls an anderen Grenzabschnitten des römischen Reiches praktiziert wurde.

Was die Siedlungsverhältnisse auf der rechten Rheinseite betrifft, hatte Caesar zunächst unmissverständlich betont, dass das Land an Hoch- und Oberrhein zu seiner Zeit von Germanen in Besitz gehalten und kontrolliert wurde, ohne jedoch genauere geographische Angaben zu liefern. Ca. 150 Jahre später vermittelt Tacitus in seiner Germania ein völlig anderes Bild. Er rechnet die Bewohner jenseits von Rhein und Donau nicht zu den germanischen Stämmen. Den Boden der so genannten agri decumates, dessen Eigentumsrecht unbestimmt gewesen sei, hätten lauter unzuverlässige und aus Not unternehmungslustige Gallier in Besitz genommen. Seit der Limes gezogen und die Kastelle vorgeschoben worden seien, gelte das Land als Ausbuchtung des Reiches und damit als Teil der Provinz (Tac., Germ. 29,3). Bestätigt wird dies dadurch, dass Rom im Verlauf der Besitznahme offenbar künstliche Verwaltungseinheiten einrichten musste, die - anders als in Gallien - weithin nicht auf gewachsenen Stammesstrukturen beruhten. Bemerkenswert ist ebenso die vergleichsweise große Zahl an civitates wie ihre Namengebung, die nicht nach eingesessenen Stammesnamen erfolgte und auch im Falle der Suebi Nicrenses, der Neckarsueben um Lopodunum/Ladenburg, die Verlegenheit bei der Benennung erkennen lässt. ${ }^{15}$ Zudem erfolgte deren rechtliche Konstituierung als civitas erst vergleichsweise spät ab trajanischer Zeit. Auffallend sind auch das isolierte municipium Arae Flaviae in Rottweil oder der offenbar umfangreiche, reichsunmittelbare saltus bei Rottenburg.

Dass der von Tacitus beschriebene Zustand mit Ausnahme der sukzessiven Inbesitznahme durch Gallier und Angehörige der römischen Armee, insbesondere Veteranen von Auxiliarformationen, im Wesentlichen bereits seit augusteischer Zeit Bestand hatte, lässt sich vor allem aus der Beschreibung der Verhältnisse rechts des Rheins bei Strabo entnehmen (Strabo 7,1,2-2,4 = 290-294 C). Wie der Autor vermerkt, sind die Völker zwischen Rhein und Elbe erst durch die Kriegszüge unter Augustus seit 12 v. Chr. bekannt geworden $(7,1,4=291 \mathrm{C}$; vgl. 2,4=294 C). Die in den folgenden Mitteilungen eingestreuten historischen Nachrichten reichen bis zum Triumph des Germanicus $17 \mathrm{n}$. Chr. Da Strabo zunächst die Situation entlang des Rheins von seiner Quelle bis zu seinen Mündungen, wie er ausdrücklich betont $(7,1,3=290 \mathrm{C})$, beschreiben will und dann - von Westen nach Osten fortschreitend - die physikalischen und ethnischen Verhältnisse im Inneren der Germania magna, muss er auch die Oberrheinlande mit im Blick gehabt haben. Zu den rheinnahen Völkerschaften heißt es, dass die Römer deren Bewohner teils nach Gallien hinübergeführt hätten, teils hätten diese sich römischem Zugriff durch Abwanderung tiefer ins Landesinnere entzogen. Genaueres zu den übergesiedelten Stämmen an Hoch-, Ober- und Mittelrhein berichtet Strabo entsprechend seiner Maxime, die Verhältnisse in erster Linie im großen Überblick und angereichert allenfalls mit interessanten Einzelheiten wiederzugeben, nicht. Da die Wohnsitze der Räter, Helvetier und Vindelikier, die bis an den Bodensee reichten, festlagen (Strabo 7,1,5 = $292 \mathrm{C}$ ), sind diese Stämme jedenfalls nicht betroffen gewesen. Interessant ist aber noch seine Nachricht vom Abzug der Markomannen mit zahlreichen anderen Stammesangehörigen aus einem gut bewohnbaren Landstrich (Strabo 7,1,5= 292 C) nach Böhmen, wo Marobod ein zeitweise bedeutendes Königreich begründete (Strabo 7,1,3 = 290 C; vgl. auch Vell. 2,108). Es kennzeichnet die römische Politik, dass kurz vor der Zeitenwende L. Domitius Ahenobarbus als Befehlshaber des illyrischen Heeres

\footnotetext{
${ }^{15}$ Also germanische Sweben ohne präzise Stammeszugehörigkeit, die sich bei dem Ort Lopodunum, dessen Name keltischen Ursprungs ist, niedergelassen hatten bzw. dort siedelten, s. auch weiter unten.
} 
den östlichen Teil des somit frei gewordenen Gebietes Hermunduren zugewiesen hatte (Dio 55,10a,2; vgl. Tac., ann. 4,44,2). ${ }^{16}$

Diese literarischen Nachrichten, welche eher die Grundzüge der geschichtlichen Entwicklungen betreffen als dass sie ein differenziertes Bild vermitteln, dürfen nicht zu sehr gepresst oder für uneingeschränkt gültig erachtet werden. Weder ist vorauszusetzen, dass mit den Helvetiern ausnahmslos alle keltischen Bewohner das hier in Frage stehende großräumige Gebiet verließen, noch andererseits, dass dann alle Germanen abgewandert sind und ihre Siedlungsplätze aufgegeben haben. Wer sich jeweils den Wanderungen anschloss, dürfte nicht zuletzt auch eine Frage der Struktur und des $\mathrm{Zu}$ sammenhaltes von Verbänden gewesen sein, d. h. der Geschlossenheit unter den jeweiligen Führern. Mit dynamischen Siedlungs- und Wüstungsvorgängen in den verschiedenen Siedlungsräumen ist jedenfalls zu rechnen, worauf wir noch am Beispiel der Oberrheinlande im engeren Sinne zurückkommen werden. Beiläufigen Hinweisen bei Caesar (B. G. 6,24,2 f.) ist etwa zu entnehmen, dass zu seiner Zeit keltische Volcae Tectosages mitten unter den Germanen die fruchtbarsten Gegenden um den Hercynischen Wald in Besitz hätten. Er nimmt dies zum Beweis für eine frühere kriegerische Überlegenheit der Kelten über Germanen und für eine west-östliche Wanderbewegung. Weitgehend zu fehlen scheinen aber archäologische Spuren aus der Zeit des Spätlatène in Südwestdeutschland auf der Baar und nördlich des Hochrheins; dies allerdings anders als weiter östlich zwischen Schwarzwald und Nördlinger Ries vor allem im Bereich nördlich der Donau, wo sie jedenfalls bis über die Zeitenwende hinaus nachgewiesen sind. Aber ebenso fehlen in diesem Bereich bislang auch frühgermanische Funde, was jedoch nach wie vor Gegenstand kontroverser Ansichten in der Forschung ist. Obgleich aus späterer Zeit stammend, lassen die Verehrung des Mercurius Cimbrianus und der berühmte Grenzstein inter Toutones bei Seiopa/Miltenberg, die uns inschriftlich überliefert sind, ${ }^{17}$ vermuten, dass eine germanische Restbevölkerung weiterhin in von Rom kontrollierten Gebieten sesshaft war, oder sie erhielt die Erlaubnis, sich in diesen niederzulassen. Letzteres gilt jedenfalls für Suebenscharen, die unmittelbar auf der östlichen Rheinseite im Verlauf des frühen 1. Jahrhunderts n. Chr. siedelten. ${ }^{18}$ Davon unabhängig ist zu fragen, ob die Unterschiede bei den rheinnahen Bewohnern zwischen Kelten und Germanen wirklich so fundamental waren, wie Caesar es uns glaubhaft machen will, ob wir es also mit zwei scharf voneinander geschiedenen Ethnien zu tun haben mit jeweils eigener Sprache, Religion, geistiger und materieller Kultur und gesellschaftlicher Struktur. Auf die Frage, inwieweit Kelten und Germanen eine diesbezügliche übergreifende Identität ausgebildet haben, wollen wir an dieser Stelle nicht eingehen. Beeinflussung und Übergänge sind nicht nur vorauszusetzen, sondern können auch der literarischen Überlieferung entnommen werden. Nach Caesar waren die Ubier wegen der Nachbarschaft zu den Galliern zivilisierter, weil sie sich an gallische Sitten gewöhnt hatten (Caes. B. G. 4,3,3). Welche Kriterien in antiker Sicht die

\footnotetext{
${ }^{16}$ Für den Bereich zwischen Donau und Fuß der Alpen hatte man bisweilen eine fast völlige Verödung in der Spätlatènezeit angenommen, was aber durch neuere Forschungen in dieser Form nicht bestätigt werden konnte. Nach Durchsicht des gesamten archäologischen Materials zeigen die Kartierungen bei WIELAND 1996 einen deutlichen Unterschied zwischen den südlich und nördlich der Donau gelegenen Zonen, wobei der Süden weit weniger dicht bevölkert gewesen zu sein scheint; vgl. dazu auch schon FISCHER 1988, bes. 238. Dies wiederum wurde von ZANIER 2004 hinterfragt, der archäologisch nicht leicht fassbare Streusiedlungen annimmt ohne auffällige oppida wie in Alteburg-Rheinau oder Tarodunum bei Kirchzarten, s. dazu weiter unten.

${ }^{17}$ Merkurinschriften s. CIL XIII 6604 f. (Miltenberg); vgl. auch AE 1921, 52 (Heiligenberg b. Heidelberg); CIL XIII 6742 und AE 1990, 742 (beide aus Mainz mit plausibler Ergänzung); Toutonenstein: CIL XIII 6610.

${ }^{18}$ Genaueres dazu weiter unten.
} 
Unterschiede ausmachten, zeigt die Charakterisierung durch Strabo $(7,1,2=290 \mathrm{C})$ : Gleich jenseits des Rheins wohnen neben den Kelten nach Osten gekehrt die Germanen, wenig verschieden vom keltischen Stamme außer durch größere Roheit, Körpergröße und Blondhaarigkeit, im Übrigen aber an Gestalt, Sitten und Lebensweise, wie wir die Kelten geschildert haben. ${ }^{19}$ Ariovist hatte zuvor gegen Sold im Dienst der Sequaner gestanden, eine seiner beiden Frauen, die Schwester des Königs der Noriker, war Keltin; er beherrschte die gallische Sprache infolge langer Übung, und seine Germanen hätten gallisches Land und gallische Zivilisation schätzen gelernt. Auch die Namen der Triboker und Nemeter gelten als keltisch. Wo sie einst im germanischen Raum saßen, ist unbekannt. Andererseits sind typisch germanische Spuren in ihrem Siedlungsgebiet westlich des Rheins vergleichsweise spärlich, wobei zudem deren zeitliche und sachliche Zuordnung problematisch ist. Dass Caesar seiner Grundintention folgend Gallier und Germanen wesentlich schärfer gegeneinander abgrenzt, zeigt der von der Forschung viel behandelte Exkurs über die Sitten bei Gallier und Germanen im 6. Buch im Anschluss an den zweiten Rheinübergang 53 v. Chr. (B. G. 6,11-28). Ähnlich verhält es sich mit der Charakterisierung der Germanen durch Pomponius Mela (3,25-28).

In der Bilanz wird man spätestens seit der Zeit Caesars, dann im Verlauf der weiteren Jahrzehnte aber verstärkt, von einer gewissen kulturellen Angleichung zwischen Kelten und Germanen zumindest in den Kontaktzonen ausgehen müssen, wobei die Frage der Selbstzuordnung der Bevölkerung zu diesen oder anderen übergreifenden und eigenständigen Identitätsgruppen mangels Selbstzeugnissen ein schwer lösbares Problem darstellt. Es sei an dieser Stelle die konzise Feststellung von Dieter Timpe aufgegriffen, wonach für den Fall, dass ethnische Organisation verstanden werden darf als institutionell verfestigte, ständige Interaktion einer sich exklusive Identität und Eigennamen zuschreibenden, in einem bestimmten Raum konstant existierenden Menschengruppe, diese nicht über die Ebene der Stämme hinausging, was eine gewisse Verwandtschaft zwischen diesen Populationen sowie übergreifende Lebensformen und gleichartige Bedürfnisbefriedigung nicht ausschließt, jedoch nicht erlaubt, von einem übergreifenden Ethnos (,Volk') etwa der Kelten oder Germanen zu sprechen. ${ }^{20}$

Wenn wir den Blick auf die historischen Entwicklungen im enger begrenzten Hoch- und Oberrheingebiet richten, ist den caesarischen Berichten zu entnehmen, dass nach dem Sieg über Ariovist die Truppen Caesars in den folgenden Jahren vorwiegend im Inneren Galliens operierten. Im Bereich des Oberrheins, bei den Helvetiern und den sich westlich anschließenden Sequanern blieb es im Ganzen ruhig, auch wenn sich dieser Stamm am großen gallischen Aufstand unter Vercingetorix 52 v. Chr. beteiligte. Nicht von ungefähr sah Caesar in den Sequanern einen besonders renitenten Gegner und verlegte am Ende des Gallischen Krieges zwei Legionen in ihr Gebiet. ${ }^{21}$ Erst nach dem Ende der Bürgerkriege zwischen Caesar und Pompeius ist ein verstärktes Interesse Roms auch an der Sicherung der Lage am Oberrhein erkennbar. Insbesondere galt es, den bedeutenden Verkehrsweg vom Mittelmeer, die Rhône aufwärts und weiter bis ins Hochrheintal, unter Kontrolle zu halten. Hierzu diente ein bewährtes Mittel römischer Sicherungspolitik in neu gewonnenen Gebieten, nämlich die Anlage von Veteranenkolonien. Einer Inschrift auf dem monumentalen Grabmal des L. Munatius Plancus im südlich von Rom gelegenen Gaëta ist zu entnehmen, dass dieser Gefolgsmann Caesars

\footnotetext{
${ }^{19}$ Vgl. zur Charakterisierung der Germanen auch App., Celt. frgm. 1,3.

${ }^{20}$ TIMPE 1998, 7-17 mit weiterführenden Überlegungen.

${ }^{21}$ Vgl. die zusammenfassende Darstellung bei Caes., B. G. 6,12; Stationierung zweier Legionen und der gesamten Reiterei ebendort s. Caes, B. G. 7,90,4; zuvor schon Besetzung von Vesontio/Besancon s. Caes., B. G. 1,38,7; Getreidelieferungen befohlen: Caes., B. G. 1,40,11; 48,2; früheres Winterlager ebendort Caes., B. G. 1,54,2.
} 
die Kolonien Lug(u)dunum (das heutigen Lyon) und die colonia Raurica (Augst) gegründet hat. Üblicherweise wird beides mit der Statthalterschaft des Plancus 44/43 v. Chr. in der Gallia comata verbunden, der damals vielleicht im Gebiet südlich des Hochrheins einen Sieg über die Raeter feierte, welcher ihm einen Triumph einbrachte (Abb. 3 a-c). ${ }^{22}$ Dieser Ansicht zufolge war schon etwa ein Jahr zuvor die colonia Iulia Equestris (Nyon am Genfer See) deduziert worden. ${ }^{23}$ Während aber Lug(u)dunum mit einer inzwischen nachgewiesenen, unweit gelegenen spätlatènezeitlichen Vorgängersiedlung offenbar rasch aufblühte, haben das Fehlen von archäologischen Spuren in Augst aus der Zeit vor Augustus, also vor 27 v. Chr., Zweifel an der traditionellen Datierung geweckt. Genährt wurden diese durch den Fund von Fragmenten zweier gleichlautender Inschriften auf Bronzeplatten sowie durch den Zusatz Augusta im Namen der Kolonie Augusta Raurica (Abb. 4). ${ }^{24}$ Dies hat zu dem Schluss geführt, dass die ursprünglich geplante und bereits rituell vollzogene Gründung der Kolonie in der Sache erst einige Zeit später unter Augustus realisiert wurde. Auch eine allerdings wenig wahrscheinliche Verlagerung der Kolonie von Basel nach Augst wurde erwogen. Nach einer neueren Theorie sind jedoch die Koloniegründungen von Augst und von Nyon nicht zwingend in spätcaesarische Zeit zu datieren oder gar mit der Statthalterschaft des Plancus in Gallien 44/43 v. Chr. zu verbinden, zumal Plancus nachweislich noch 22 v. Chr. in Rom ein Amt ausgeübt hat. Wir lassen dies hier offen.

\section{Zur Bevölkerungsgeschichte der Oberrheinlande im Spiegel der archäologi- schen Quellen}

\section{a. Von der Spätlatène- zur Römerzeit}

Während die literarische Überlieferung ihrer Eigenart entsprechend eher größere Räume und Zusammenhänge im Blick hat, bieten die archäologischen Zeugnisse primär punktuelle Interpretationsansätze, die unsere Aufmerksamkeit auf die kleinräumigeren Verhältnisse lenken, in unserem Fall also dezidiert auf die Bereiche von Hoch- und Oberrhein. Dabei kommen die historischen Prozesse aus einer etwas anderen Perspektive in den Blick als durch die literarischen Quellen mit ihrer romzentrischen Sicht. Trotz bemerkenswerter Fortschritte in den letzten Jahren hat die archäologische Forschung aber noch keine letzte Klarheit erbracht über die Besiedlungsgeschichte an Oberrhein und Hochrhein von der Spätlatènezeit der Stufe D 2 bis in die tiberische bzw. frühclaudische Zeit, d. h. von ca. 85/80 v. Chr. bis etwa $50 \mathrm{n}$. Chr. Dieses betrifft nicht nur die Interpretation verschiedener Funde und Befunde als solche sondern auch mögliche Organisationsformen der Bevölkerung. Nachweisbar sind auf jeden Fall räumlich unterschiedliche Entwicklungsvorgänge entsprechend den unterschiedlichen geographischen, wirtschaftlichen und politischen Voraussetzungen; zu bedenken ist immer auch der unterschiedliche Forschungsstand in den verschiedenen Zonen. Generell ist allerdings bis in den nördlichen Bereich der Oberrheinlande ein deutlicher Abbruch der Besiedlung ab ca. 85/80 v. Chr. festzustellen, ein Hiatus, der sich offenbar bis in die

\footnotetext{
${ }^{22}$ Hierzu MATIJEVIĆ 2008, 141-168.

${ }^{23}$ CIL X 6089 = ILS 886 : L(ucius) Munatius L(uci) f(ilius) L(uci) n(epos) L(uci) pron(epos) / Plancus co(n)s(ul) cens(or) imp(erator) iter(um) VIIvir / epulon(um) triump(havit) ex Raetis aedem Saturni /fecit de manibi(i)s agros divisit in Italia / Beneventi in Gallia colonias deduxit / Lugudunum et Rauricam.

${ }^{24}$ AE 1974, 435 = AE 2000, 1030: L(ucio) Octa[vio . f(ilio)] / nuncu[patori] / colonia P[aterna] / [[M[unatia Felix]]] / [Apollinaris] / [Augusta Emerita] / [Raurica] / [publice] // ---.
} 
spätaugusteische Zeit fortsetzte und sich auch an verschiedenen Orten durch den Abbruch landwirtschaftlich genutzter Flächen mit der Folge von rascher Bewaldung derselben zu erkennen gibt. Dies gilt nicht in gleichem Maße für die linksrheinischen Gebiete am Hochrhein, also der Schweiz, und auch nicht für einige unmittelbar am Rhein gelegene Siedlungen in Rückzugslage. Erst ab der späteren augusteischen Zeit und verstärkt ab Tiberius bezeugen zahlreiche archäologische Fundstellen auf beiden Seiten des Oberrheins eine zunehmend dichtere Besiedlung sowie eine zunehmend intensivere militärische Kontrolle durch Rom.

Angesichts der zahllosen Funde und Fundstellen - dabei handelt es sich allerdings weit überwiegend um Streufunde - müssen wir uns hier auf einige grundlegende Beobachtungen und markante Fallbeispiele beschränken. ${ }^{25}$

Für das späte 2. bis ins frühe 1. vorchristliche Jahrhundert lässt sich generell in den hier interessierenden Gebieten ein beachtliches Zivilisationsniveau feststellen, welches insbesondere durch Kontakte mit den antiken Kulturen des Mittelmeerraumes bedingt war. Ein spezialisiertes Handwerk neben der dominierenden Landwirtschaft bezeugt eine arbeitsteilige Wirtschaftsstruktur, erste Formen einer Geldwirtschaft sind auszumachen, personifizierte Gottheiten und auch Tempelbauten belegen entwickelte Ausdrucksformen der Frömmigkeit, vor allem aber legen die Siedlungsstrukturen mit Höhensiedlungen (sog. oppida) und größeren Ansiedlungen im flachen Gelände Zeugnis ab von wirtschaftlicher und sozialer Differenzierung. Diese war offensichtlich auch mit einer differenzierten Machtstruktur und somit einer gewissen adligen Oberschicht verbunden, ohne dass es zu einer umfassenden staatlichen Ordnung mit entsprechenden Verwaltungsstrukturen gekommen wäre. Bekanntlich setzt ein Kulturraum keineswegs die politische Einheit voraus wie auch das Umgekehrte nicht zwingend gilt.

Die Karte (Abb. 5) zeigt zentrale spätlatènezeitliche Großsiedlungen an Hochund Oberrhein, ohne dass damit Vollständigkeit angezeigt wäre. Notgedrungen bleiben die als Siedlungstyp dominierenden Einzelgehöfte unberücksichtigt. Wir können hier nur anhand einiger weniger Fundstellen etwas genauer aufzeigen, was wir heute über die historischen Entwicklungen im fraglichen Raum zur fraglichen Zeit wissen. Dabei zeichnen sich einige bemerkenswerte Veränderungen $a b$.

Aus sachlichen wie aus forschungsgeschichtlichen Gründen ist die Geschichte von Tarodunum östlich von Freiburg besonders aufschlussreich, zumal sie auch exemplarisch ist für eine sich bis in die Gegenwart immer wieder verändernde Forschungslage (Abb. 6). Der bereits genannte Ptolemaios listet nämlich in einem Streifen längs der Donau (wohlgemerkt!) $(2,15,1-3)$ als erstes die folgenden Städte (poleis) auf: Tarodunum, Arae Flaviae, Riusiava usw. Die Nennung von Arae Flaviae, dem heutigen Rottweil, belegt den Ursprung dieses Teils der Ortslisten nicht vor der Zeit Vespasians (69-79 n. Chr.), andererseits aber noch vor der formellen Einrichtung der Provinzen Ober- und Untergermanien um 85 n. Chr., da das Gebiet von Ptolemaios noch der römischen Provinz Belgica und nicht der Germania superior zugeordnet wird. Dass sich der Name Tarodunum im heutigen Zarten bzw. Kirchzarten am Ausgang des Höllentals erhalten hat, ist unstrittig, nicht dagegen, ob er bis in die vorrömische Zeit zurückreicht und mit welchen Siedlungsresten er zu verbinden ist. Nach älteren archäologischen Beobachtungen vermutete man in Tarodunum eine umfangreiche, stark befestigte Stadt, also ein bedeutendes oppidum, von dem die Umwallung in der Tat bis heute im Gelände sichtbar ist. Innerhalb des ca. 200 ha umfassenden Areals wurden zunächst keine Ge-

\footnotetext{
${ }^{25}$ Für das südliche, rechtsrheinische Oberrheingebiet verweisen wir an dieser Stelle noch einmal besonders auf die aktuelle Arbeit von BLÖCK 2016.
} 
bäudespuren mit Ausnahme zweier römerzeitlicher Räume in geringem Abstand zueinander beobachtet. Diesbezüglich hat sich in den letzten Jahren die Forschungslage grundlegend geändert. Vor ca. 20 Jahren gelang in Zarten im unmittelbaren Vorfeld des von dem Wall umschlossenen Areals die Entdeckung einer ca. 14 ha umfassenden Siedlung der Spätlatènezeit, die man mit der lange gesuchten polis Tarodunum gleichsetzte, was jüngst aber schon wieder infrage gestellt wurde. Hier wurden keltische Goldmünzen als Imitate griechischer Statere geprägt, und es gibt zuverlässige Hinweise darauf, dass die Bevölkerung nicht ausschließlich von der Landwirtschaft, sondern auch vom Handwerk lebte. ${ }^{26}$ Dies zeigt die Fertigung keramischer Produkte, von Schmuck aus Glas oder die Verarbeitung von Erzen, woher und ab wann auch immer. Scherben italischer Weinamphoren belegen zudem einen beachtlichen Lebensstandard mit mediterranen Einflüssen. Offenbar war mit Errichtung einer weitläufigen Befestigung eine Konzentration der Einzelsiedlungen im Umfeld geplant, was aber nicht mehr realisiert wurde. Die vor den Toren des Walles gelegene Siedlung war jedenfalls um 85/80 v. Chr., also noch vor der Eroberung Galliens durch Caesar, verlassen worden. Über die spezifischen Gründe des Abzugs und das Schicksal der Siedler können wir nichts aussagen. Neben äußerem Druck können auch wirtschaftliche Gründe oder Verwerfungen innerhalb der Bevölkerung oder auch alles zusammen nicht ausgeschlossen werden. Neuerdings möchte Lars Blöck jedoch den Namen Tarodunum erst mit einem römerzeitlichen vicus frühestens aus der Zeit um die Mitte des 1. Jahrhunderts n. Chr. verbinden, zu dem auch die erwähnten römerzeitlichen Baureste innerhalb des Wallbereichs gehören. Die Folgerung einer frühen Wegetrasse über das Dreisamtal in den Schwarzwald und die Postulierung einer militärischen Verbindungslinie vom Rheintal zu den Kastellen an der oberen Donau vor der flavischen Zeit wird damit erneut problematisch. Sie war einst ebenso wie die Annahme eines claudischen Kastells in Riegel am nördlichen Rand des Kaiserstuhls zunächst behauptet, dann negiert, vor wenigen Jahren wiederum vertreten worden, wird jetzt aber erneut abgelehnt bzw. als unbewiesen in Frage gestellt mit Folgen auch für die Rekonstruktion der militärischen Besetzungsgeschichte in früher römischer Zeit, wie wir noch sehen werden.

Wie für Tarodunum lässt sich die Aufgabe spätlatènezeitlicher offener Siedlungen kurz nach Beginn des 1. vorchristlichen Jahrhunderts und ein Rückzug in besser geschützte Plätze auch für die Bevölkerung weiterer Siedlungen an Ober- und Hochrhein nachweisen wie etwa in Altenburg-Rheinau (Abb. 7) ${ }^{27}$ und weiter bis ins Unterelsass. Hier dürfte nach den archäologischen Untersuchungen der jüngeren Vergangenheit das mächtige oppidum auf dem Bergsporn Fossé des Pandours bei Saverne/Zabern, das nördlich der Burgundischen Pforte die nächste günstige west-östliche Traversale zwischen dem zentralen Gallien und dem Rhein kontrollierte, ein oder auch der Zentralort der Mediomatriker gewesen sein. ${ }^{28}$ Es wurde um 70 v. Chr. offenbar auf äußeren Druck hin, über den ja auch Caesar $(1,37,3)$ berichtet, verlassen und in das weiter im Inneren Galliens gelegene Divodurum/Metz verlagert. Damit war auch Raum für die spätere Ansiedlung der Triboker geschaffen. ${ }^{29}$ Hinsichtlich des Hiatus in der Besiedlung nach Abbruch in der Phase Latène D 2 lässt sich am Oberrhein lediglich noch im Bereich von unmittelbar am Rhein gelegenen und geschützten Positionen eine Besiedlung, wenngleich auf verschiedener Basis und in unterschiedlichen Phasen, nachweisen. So wurde etwa auf dem Limberg bei Sasbach eine Kleinbefestigung mit einer im Stil eines murus Gallicus errichteten Abschnittsmauer aus der Zeitstufe Latène

\footnotetext{
${ }^{26}$ Vgl. etwa WENDLING 2004; DeHn 2005; WENDLING 2005/3.

${ }^{27} \mathrm{Zu}$ Altenburg-Rheinau s. etwa FISCHER 2004 oder BRÄUNING 2005.

${ }^{28}$ Vgl. dazu FiCHTL 2004 und FiCHTL/PIERREVELCIN 2005.

${ }^{29}$ REDDÉ 2009, 407; vgl. auch FICHTL 2000, 21-38.
} 
D 1 ergraben, die Siedlung jedoch um 60/50 v. Chr., vielleicht auch wenig später aufgegeben. ${ }^{30}$ In Breisach war zwar die Siedlung im Flachland (Breisach-Hochstetten) mit auch hier nachgewiesenen bemerkenswerten Importen aus Italien ebenfalls zu Beginn des 1. Jahrhunderts v. Chr. verlassen, der Münsterberg aber nach derzeitigem Kenntnisstand erst ca. 20 Jahre später als Kleinbefestigung eines spätkeltischen Potentaten besiedelt worden (Abb. 8), wobei die zeitliche Lücke bislang nicht schlüssig zu erklären ist. ${ }^{31}$ Nach der römischen Eroberung Galliens blieb die befestigte Ansiedlung bis etwa 40/30 v. Chr. bestehen, wobei anscheinend eine einheimische Besatzung in Diensten Roms die Rheingrenze kontrollierte. Dann aber wurde Breisach geräumt und nicht weiter vom römischen Militär direkt oder indirekt als Grenzposten verwendet. Noch anders war die Situation auf dem Basler Münsterhügel, der nach Aufgabe einer im Vorfeld in der Ebene gelegenen Siedlung ab ca. 70/60 v. Chr. bis in die römische Kaiserzeit genutzt wurde, wobei sich der Siedlungscharakter in der augusteischen Zeit merklich veränderte (Abb. 9). Hier überwog zunächst deutlich der militärische Charakter mit einer starken Befestigung und Funktion als Grenzschutz, der wohl in erster Linie einheimischen Kriegern unter adliger Führung anvertraut war und nicht durch eine reguläre römische Auxiliareinheit versehen wurde. Ob hier nach Caesar auch einige römische Legionäre den Einheimischen an die Seite gestellt wurden oder Letztere auf Kosten Roms auf römische Weise militärisch ausgerüstet wurden, bleibt zu fragen. Grundsätzlich kann aus der Bezeugung römischer militaria in Siedlungen nicht ohne weiteres auf eine militärische Anlage bzw. Besatzung Roms geschlossen werden, wie etwa der Fall von Oberwinterthur mit seinen zahlreichen militärischen Funden zeigt. Entgegen früherer Annahme existierte dort nach heutigem Wissen kein Kastell, sondern um 8/9 n. Chr. entstand hier gleichsam ex nihilo und in einem Zug eine Siedlung ähnlich wie im rechtsrheinischen Waldgirmes schon gut 10 Jahre zuvor. Wie für Basel ist auch für Vindonissa/Windisch eine militärische Funktion gut nachweisbar (Abb. 10). Charakteristisch für diese Zeit ist die Verbindung von Militärstützpunkt und einheimischem oppidum, ein Verfahren vonseiten Roms, welches besonders deutlich am Titelberg in Luxemburg ab etwa 30/29 v. Chr. zu beobachten ist (Abb. 11 a-b). Bereits ab frühaugusteischer Zeit wurde in Basel aber der zivile Charakter bestimmend. Die Siedlungen in Basel wie in Breisach können in der caesarischen bis frühaugusteischen Zeit wohl als regionale politische, militärische und wirtschaftliche Zentren angesehen werden. Vom rechten Hochrhein liegen mit Ausnahme des unmittelbaren Umfeldes von Basel nur ganz vereinzelte Streufunde vor, welche einer Periode, die von der Stufe Latène D 2 bis in die augusteische Zeit reicht, zugerechnet werden können.

Zusammengefasst ist mit Blick auf die Jahrzehnte unmittelbar vor der römischen Besitznahme eine deutliche Tendenz zu beobachten, offene Siedlungen aufzugeben oder in mehr oder weniger befestigte Anlagen überzusiedeln, was wohl in erster Linie zunehmender äußerer Bedrohung geschuldet ist. Dass diese irgendwie mit den Zügen des Ariovist in Verbindung steht, ist möglich, vielleicht auch wahrscheinlich, aber letztlich nicht zu beweisen. Immerhin war bereits um $71 \mathrm{v}$. Chr. Ariovist mit einer Söldnerschar, angeworben von Sequanern und Avernern, über den Hochrhein hinweg nach Gallien gezogen und hatte 61 v. Chr. die Häduer in Zentralgallien besiegt und diese tributpflichtig gemacht (Caes. B. G. 1,31,12; vgl. auch Dio 38,34,1). Möglicherweise ging diese nachzuweisende Siedlungskonzentration an einigen wenigen Orten

\footnotetext{
${ }^{30}$ FingerLIN 1973 und FingERLIN 1975; dazu SCHÖNBERGER 1985, 336; 353; 434 Anm. 46; WENDLING 2005/2; REDDÉ 2009, 407 f.

${ }^{31} \mathrm{Zu}$ der Siedlung in Breisach-Hochstetten s. STORK 2007; zum Münsterberg in Breisach s. WENDLING 2005/1 (auch zu Breisach-Hochstetten); WENDLING 2006; WENDLING 2007. - Zu Breisach in römischer Zeit s. BENDER/POHL 2005.
} 
aber auch einher mit einem inneren sozialen und politischen Strukturwandel mit einer neu formierten Führungsschicht.

\section{b. Militärische Kontrolle und zivile Erschließung}

Vorausgeschickt sei der Hinweis, dass wir bislang keine Belege haben, die eine dauerhafte Stationierung regulärer Einheiten unterhalb von Basel vor dem Ende der Regierungszeit des Augustus beweisen können. Die Phantasie der Forscher hatte lange Zeit eine Notiz bei dem römischen Historiker Florus $(2,30,26)$ beflügelt, wonach Drusus, der die ersten großen Feldzüge Roms nach Germanien zwischen 12 und 9 v. Chr. kommandierte, entlang der Rheinfront mehr als 50 Kastelle errichtet habe. Klar ist, dass sich Florus diese Aussage nicht völlig aus den Fingern gesogen haben kann, aber die bekanntlich von diesem Autor effekthascherisch und rhetorisch aufgeputzten Mitteilungen mahnen zur Vorsicht. Trotzdem hatte die Notiz auch am Oberrhein, und hier besonders auf seiner linken Seite, zu einer geradezu hektischen Suche nach solchen Kastellen geführt, und vermeintliches Entdeckerglück ließ auch nicht lange auf sich warten. Man glaubte solche Anlagen in der elsässischen Ebene in Basel, Kembs, Ehl, Kunheim-Biesheim, Straßburg und Forstfeld lokalisieren zu können. ${ }^{32}$ Ein Übriges tat der Grabstein eines Reiters einer ala Petriana aus Argentorate/Straßburg, den man willkürlich und ohne triftige Gründe mit J.-J. Hatt in die Jahre 12-10 v. Chr. datierte (Abb. 12) ${ }^{33}$ Die archäologischen Funde und Befunde können diese Einschätzung jedoch nicht bestätigen. Von den vorgeschlagenen Stationierungsorten sind Kembs, Ehl und Forstfeld archäologisch gänzlich ungesichert. Für den Limberg bei Sasbach am Kaiserstuhl wird eine augusteische Zeitstellung einerseits bezweifelt, andererseits aber doch an diesem Ort ein kleineres Lager im Zusammenhang mit einer einheimischen Kleinsiedlung bereits für die Zeit des „Dangstettenhorizontes“ mit dem dort zwischen 15 und 9/8 v. Chr. vorhandenen Lager mit Teilen der 19. Legion sowie Hilfstruppen postuliert. ${ }^{34}$ Auch ein Zusammenhang mit den Drususfeldzügen als Nachschublager wird erwogen, beides, nämlich Datierung und Funktion, sind beim derzeitigen Forschungsstand aber eher unwahrscheinliche Hypothesen. Für möglich gehalten wird auch eine Nutzung der militärischen Anlage erst in tiberischer Zeit. In diese Phase gehören jedenfalls die Kastelle in Biesheim-Oedenburg - eventuell das antike Argentovaria - mit Besatzung möglicherweise einer ala oder auch einer gemischten Einheit. Ein erstes Kastell wurde hier um 20 n. Chr. angelegt (Kastell B), das zu Beginn oder im Laufe der 30er Jahre aufgegeben und durch einen kleinen Posten ersetzt wurde. Zu Beginn oder in der Mitte der 40er Jahre erfolgte dann der Bau eines neuen Kastells (Kastell A), welches bis zum Beginn der Herrschaft Vespasians Bestand hatte. ${ }^{35}$ In tiberische

\footnotetext{
${ }^{32}$ Die frühere Forschung wird vor allem durch FORRER 1927 und FORRER 1935 dokumentiert. Aus jüngerer Zeit folgenreich HATT 1978, 32 oder HATT 1980, bes. zu Straßburg. Dazu aber mit Recht kritisch REDDÉ 2005.

${ }^{33}$ CIL XIII 11605 = ILS 9136: Marti / Loucet(io) / v(otum) s(olvit) l(ibens) l(aetus) m(erito) / Fittio Cond/olli f(ilius) eq(ues) al/a Petri(ana) Treve(r). - Mars Loucetius wurde vor allem im treverischen Raum verehrt. Im dortigen Stammesgebiet rekrutierte Reiter gehörten zu den besten in ganz Gallien. Die Inschrift ist zweifellos in die frühe Kaiserzeit zu datieren. Man kann mit guten Gründen annehmen, dass T. Pomponius Petra, der unter anderem zwischen 14 und 19 praef(ectus) Germanici Caesaris war (CIL XI 969 [Regium Lepidum/Reggio Aemilia]) der erste und zugleich namengebende Kommandeur der Einheit war (PME R 17). Auf die Frage der Truppendislokation in iulisch-claudischer Zeit im Bereich des obergermanischen Heeres kommen wir an anderer Stelle zurück.

${ }^{34}$ Dieses ist das bislang einzige, wirklich gut dokumentierte Lager am Hochrhein auf seinem nördlichen Ufer. S. dazu grundlegend DANGSTETTEN I-III 1986/2006.

${ }^{35}$ Grundlegend und zusammenfassend REDDÉ 2009, 403 f.; vgl. schon WIEGELS 1983 zu gestempelten Ziegeln römischer Truppen im Oberrheingebiet aus der Mitte des 1. Jahrhunderts n. Chr.
} 
Zeit datieren zudem Militäranlagen in Augst ${ }^{36}$, Zurzach ${ }^{37}$ und Konstanz ${ }^{38}$, vor allem aber auch die Lager der legio XIII Gemina in Vindonissa und der legio II Augusta in Argentorate/Straßburg, wo jedenfalls die ältesten Spuren römischen Militärs nicht vor 14 n. Chr. zurückreichen.

Grundsätzlich liegen bislang keine Hinweise dafür vor, dass die augusteische Okkupation, aber auch nicht tiberische Sicherungsmaßnahmen dauerhaft über die Uferzone des Rheins hinaus auf rechtsrheinisches Gebiet übergegriffen haben. Strittig ist neuerdings wieder die Annahme eines claudischen bis frühflavischen Kastells in Riegel. Eine polygonale Holz-Erde-Befestigung mit vorgelagertem Spitzgraben aus frühflavischer Zeit interpretiert Blöck jetzt vielmehr als Überreste einer Befestigungsanlage eines rein zivilen vicus, der erst in frühflavischer Zeit nach lange vorausliegendem $\mathrm{Ab}$ bruch einer latènezeitlichen Besiedlung gegründet wurde. Dieser entwickelte sich fortan jedenfalls als ziviler Zentralort u.a. mit Forum, Tempelanlagen und einer bemerkenswerten Basilika zu einem Vorort mit möglicherweise privilegiertem latinischen Recht seiner Bewohner. ${ }^{39}$ Als Konsequenz dieser jüngsten Ansicht wird auch die Trasse der ,Dreisamtalstraße“ vom Rhein über den Schwarzwald mit Verbindung an die Donau aus iulischer oder auch erst ab claudische Zeit wieder infrage gestellt und in die Regierungszeit Vespasians datiert (Abb. 13). Damit würde sie etwa in die gleiche Zeit gehören, als der Legat Cn. Pinarius Clemens mit dem 73/74 n. Chr. unternommenen Feldzug das Dekumatland unter römische Kontrolle brachte und in diesem Zusammenhang die militärisch wichtige Route von Straßburg durch das Kinzigtal zu den Kastellen an der oberen Donau öffnen ließ. ${ }^{40}$ Dies jedenfalls lehrt der berühmte Meilenstein von Offenburg mit dem Vermerk iter ab Argentorate in Raetiam. ${ }^{41}$ Dort und im benachbarten Zunsweier sind jetzt auch Militäranlagen gesichert, was schon aufgrund des Grabsteins eines Centurio der cohors I Thracum anzunehmen war (Abb. 14). ${ }^{42}$ Eine strategische Bedeutung kann dann eine Dreisamtaltrasse oder auch eine solche durch das Glottertal, wo aber bislang entsprechende Befunde fehlen, nicht mehr gehabt haben, zumal auch das Kastell Brigobannis/Hüfingen als Knotenpunkt ab flavischer Zeit ausschied. ${ }^{43}$ Die Frage scheint beim derzeitigen Stand ebenso wenig zu beantworten zu sein wie die damit eng zusammenhängende Annahme oder Ablehnung der Existenz eines Kastells in Riegel in claudisch-frühvespasianischer Zeit. Im Fluss ist nach wie vor auch die Diskussion über Verlauf und Datierung einer Verbindung von Vindonissa über

\footnotetext{
${ }^{36}$ DeSChLER-ERB U.A. 1991 und DesChLER-ERB 1999, nicht ohne gewisse Vorbehalte in der neueren Literatur, s. den Hinweis bei REDDÉ 2009, 410 mit Anm. 31.

${ }^{37} \mathrm{Zu}$ Tenedo/Zurzach s. HÄNGGI/DoswALD/ROTH-RUBI 1994, bes. 140.

${ }^{38}$ MAYER-REPPERT 2003. - Unklar ist die Deutung der archäologischen Spuren in Untereggingen im südlichen Wutachtal, s. auch weiter unten Anm. 44.

${ }^{39}$ S. zuletzt BLÖCK 2016, bes. 138-147; davor zusammenfassend mit teilweise abweichender Interpretation DREIER 2005.

${ }^{40}$ FILTZINGER 1986, 48.

${ }^{41}$ CIL XIII 9082 = XVII 654 = ILS 5832 (Offenburg): [Imp(eratore) Vespasiano Caesare] / [Aug(usto) pontif(ice) max(imo) trib(unicia) pot(estate) V imp(eratore)] / [XIII p(atre) p(atriae) co(n)s(ule) V design(ato) VI] / [Imp(eratore) T(ito) Caesare Aug(usti)f(ilio)] / [co(n)s(ule) III design(ato) IV] / Caesar[e Aug(usti) f(ilio) Domitia]no / co(n)s(ule) [II design(ato) III] / Cn(aeo) Cor[nelio Clemen]te leg(ato) [Aug(usti) pr(o) pr(aetore)] / iter de[rectum ab Arge]ntorate / in R[aetiam] / A[rgentorate.

${ }^{4}$ CIL XIII 6286 (Offenburg): L(ucio) Valerio Alb/ino dom(o) +++[---] / |(centurio) c(o)ho(rtis) I Trhacu [m] / ann(orum) LXV sti(pendiorum) XXIII / h(ic) s(itus) [e(st)].

${ }^{43} \mathrm{Zu}$ Brigobannis/Hüfingen s. die Übersicht bei ECKERLE/FINGERLIN 2005.
}

http://www.fera-journal.eu 
Tenedo/Zurzach, Iuliomagus(?)/Schleitheim und das Tal der Wutach an die obere Donau. $^{44}$

Eine intensive zivile römerzeitliche Besiedlung setzt im südlichen Oberrheingebiet in tiberischer Zeit ein, im nördlich daran anschließenden Bereich im Wesentlichen jedoch erst unter Nero. Im Gegensatz zur Ansicht, dass die rechtsrheinischen Militäranlagen wie Sasbach oder Riegel entweder dem Schutz einer frühen Straßenverbindung vom Oberrhein über den Schwarzwald zur Donau dienten oder eine Vorfeldsicherung für die linksrheinischen Militäranlagen darstellten, postuliert die aktuelle Forschung eine zunächst völlig militärfreie Zone nördlich und östlich von Hoch- und Oberrhein als ein militärisch vor allem von Argentorate, Argentovaria und Vindonissa überwachtes Glacis. ${ }^{45}$ Dieses sei dann in der südlichen Zone von Neusiedlern mit der Anlage von Villen und Einzelhofsiedlungen kolonisiert worden, ohne dass diese sich zwingend wie etwa im östlichen Raetien an den großen Verkehrswegen orientiert hätten. Dabei deuten verschiedene Indizien darauf hin, dass Neusiedler aus Gallien die entscheidende Rolle spielten. Eine eingehende, chronologisch differenzierte Analyse des dann einsetzenden Prozesses mit verschiedenen Siedlungstypen wie Streuhofanlagen, vici oder villae ist an dieser Stelle nicht möglich. Besonders hingewiesen sei aber auf die villa urbana bei Heitersheim, südlich von Freiburg mit Beginn bereits um 30 n. Chr., eine Anlage im besten Baustil italischer Landhäuser mit mindestens $20 \mathrm{~km}^{2}$ Landbesitz. Sie ist die größte bislang bekannt gewordene römische Einzelsiedlung am rechten Oberrhein mit einer zentralen Lage im dortigen Straßennetz und fruchtbarem Umfeld. Neben ihr verdient die römische Villa von Laufenburg am Hochrhein aus derselben Zeit besondere Beachtung. Weitere größere Anlagen in Form von villae rusticae existierten spätestens um die Mitte des 1. Jahrhunderts n.Chr. auch an anderen Orten. Dies und andere Hinweise legen Zeugnis dafür ab, wie eine neue Generation der einheimischen Oberschicht ihren Lebensstil zunehmend nach mediterranem Vorbild veränderte. Landwirtschaft und Kleingewerbe dominierten offenbar die Wirtschaft. Zumindest erwähnt seien aber auch die mit der Zeit zunehmende Erschließung und Nutzung heißer Quellen wie in Baden (Aquae Helvetiae) in der Schweiz, Badenweiler und Baden-Baden sowie die Nutzung von Erzlagerstätten wie den Silberabbau bei Sulzburg. Etwas unklar sind die diesbezüglichen Entwicklungen im linken Oberrheintal, wo sich anscheinend die traditionellen Strukturen in den ländlichen Bereichen länger hielten, was vielleicht auf eine geringere Bevölkerungsfluktuation zurückzuführen ist. Allerdings beschränken sich die hier nachgewiesenen Siedlungsspuren in erster Linie auf den Umkreis der oppida, im Bereich des Sundgaus fehlen sie bislang mit Ausnahme von Sierentz nahezu völlig. ${ }^{46}$ Hinweise sind aber auch aus Oedenburg, wenngleich erst aus vergleichsweise später Zeit, bekannt. Grundsätzlich müssen in der linksrheinischen Zone verstärkt Forschungslücken vor allem wegen des Rebanbaus im Vorfeld der Vogesen und der schwierigeren Siedlungsbedingungen in der Ebene mit den Feuchtzonen in Betracht

\footnotetext{
${ }^{44}$ In Untereggingen, Gem. Eggingen, Kreis Waldshut wurde auf einem Plateau oberhalb der Wutach Ende des vergangenen Jahrhunderts ein Spitzgraben entdeckt, der mit einem frührömischen Militärstützpunkt in Verbindung gebracht wird. Die Straßenverbindung als solche ist auch in der Tabula Peutingeriana verzeichnet.

45 Ältere Kartierung der Besiedlungszonen einschließlich der vielleicht auf die Forschungslage zurückgehenden Lücken bei WEBER-JENISCH 1995, 82 Abb. 40. - Zum südlichen Oberrheingebiet östlich des Flusses jetzt ausführlich BLÖCK 2016, passim mit zahlreichen Kartierungen in der Beilage.

${ }^{46} \mathrm{Zu}$ Sierentz s. WOLF 2005; MURER-RoTH-ZEHNER 2009.
} 
gezogen werden. ${ }^{47}$ Betont wird, dass es in diesem Bereich nur wenige Siedlungen gibt, die früh, also noch vor Beginn des 1. Jahrhunderts n. Chr., „,romanisiert" wurden. ${ }^{48}$

Dennoch besteht kein Anlass zu unterschiedslosen Verallgemeinerungen, welche auch nicht aus den archäologischen Funden und Befunden abzuleiten sind. Hingewiesen sei hier nur auf swebische, aber offenbar nicht stammesmäßig organisierte Siedlergruppen im nördlichen Oberrheintal bei Groß-Gerau oder auf die Neckarsweben um Ladenburg und nicht zuletzt auf die Oberrheinsweben bei Diersheim im rechtsrheinischen Vorfeld von Straßburg. Nach Entdeckung eines weiteren größeren Gräberfeldes bei Diersheim vor wenigen Jahren hat sich deren aus den Sachgütern erschlossene Zuordnung zu den Sweben erneut bestätigt. Rom tolerierte sichtlich diese elbgermanischen Gruppen, welche sich gleichsam als Militärsiedler und Milizen an der Verteidigung der Grenzen beteiligen sollten, aber sich erst sekundär in der ersten Hälfte des 1 . nachchristlichen Jahrhunderts im rechtsrheinischen Raum niedergelassen hatten. Aufgrund der Funde in den Waffengräbern, die zu dieser Zeit auch andernorts in Gallien nachzuweisen sind, wurde zunächst ein sukzessives Vordringen swebischer Gruppen mit oder ohne römische Weisung von Nord nach Süd vermutet. Die Diersheimer Sweben nördlich von Offenburg mit den ihnen zugehörenden Waffengräbern datierte man ab etwa der Mitte des 1. Jahrhunderts n. Chr. Sie verschwinden aber dann im Kulturgut, um plötzlich und völlig überraschend Ende des 2. Jahrhunderts n. Chr. mit deutlich wiederbelebten Beziehungen in den elbgermanischen Raum hinein aufzutauchen. ${ }^{49}$ Auf mysteriöse Weise scheint sich hier eine gewisse Identität gehalten zu haben, vielleicht beruht dies aber wiederum auf einer Forschungslücke, welche uns die Kenntnis von Zwischenstationen verstellt. Der Beginn des vor wenigen Jahren im beschriebenen Raum entdeckten weiteren ,swebischen' Gräberfeldes kann jetzt aber bereits in die tiberische Zeit datiert werden. ${ }^{50}$ Damit gerät die Ansiedlung dieser Gruppen in den Horizont der tiberischen Grenzpolitik am Rhein, zu der an anderer Stelle ausführlicher Stellung genommen werden soll. Auch die Annahme eines vergleichsweise langsamen Vordringens nach Süden lässt sich demnach in dieser Form nicht mehr halten. Ein Übriges ist einem sensationellen Inschriftfund aus dem Offenburger Raum zu entnehmen. In dieser Inschrift wird ein princeps Sueborum genannt, der offenbar Ordnungsfunktionen und Verwaltungsaufgaben in diesem Raum übernommen hatte (Abb. 15). ${ }^{51}$ Zugleich wird das Ethnikon Suebi gesichert, ähnlich wie bei den Suebi Nicrenses um Lopodunum/Ladenburg. Entsprechende germanische Funde lassen sich bei den auf die linke Rheinseite übergesiedelten germanischen Stämmen nur gelegentlich nachweisen, wobei zudem zu fragen wäre, ob sie eine ungebrochene Tradition bezeugen.

\footnotetext{
${ }^{47} \mathrm{Zu}$ den Siedlungen in der elsässischen Ebene s. besonders ROTH-ZEHNER 2005 und ROTH -ZEHNER 2010 mit Nachweis des Überdauerns von prähistorischen Elementen bis in die Regierungszeit des Tiberius.

${ }^{48}$ REDDÉ 2015, 308.

${ }^{49}$ Grundlegend NIERHAUS 1966 mit ausführlicher Erörterung auch der historischen Implikationen. - Zu den Neckarsweben jetzt SCHLEGEL 2000.

${ }^{50}$ SCHREMPP U. A. 2015 (2016); SCHREMPP U. A. 2016 (2017).

${ }^{51}$ BLÖCK/LAUBER/TRÄNKLE 2016. Der Grabstein ist vor allem im linken und oberen Bereich teilweise zerstört. Der Name des Verstorbenen ist daher nicht sicher bestimmt. Bemerkenswert aber ist der Umstand, dass der Sohn, welcher den Grabstein setzen ließ, das römische Cognomen Proculus führte. Eine exakte Datierung ist nicht möglich. Epigraphische Kriterien verweisen den Stein jedenfalls in das 1. Jahrhundert n. Chr. Eine Datierung um die Mitte desselben erscheint plausibel.
} 


\section{Ein durchaus vorläufiges Fazit}

Am Schluss dieser kursorischen Übersicht bleibt die Feststellung, dass die Siedlungsgeschichte des südlichen Oberrheins und der angrenzenden Hochrheinzone im Übergang von der Latène- zur römischen Zeit nur auf einer vergleichsweise allgemeinen Ebene als ein einheitlicher Vorgang zu werten ist. Die Integration der Gebiete in das Imperium Romanum beruhte auf unterschiedlichen Voraussetzungen und vollzog sich selbst in dem vergleichsweise kleinen Raum in unterschiedlichen Rhythmen. Dies war abhängig von der Funktion der Siedler und deren Organisation, den Kontakten derselben mit dem Mittelmeerraum, dem autonomen Entwicklungsstand, der geographischen Situation, dem konkreten Interesse der römischen Eroberer, den strategischen Implikationen und wirtschaftlichen Kontakten und nicht zuletzt der Rolle und der Eigenart des Militärs. Blicken wir auf den gallischen Großraum, so belegen etwa die geschichtlichen Entwicklungen an Orten wie Lyon, Langres oder Besançon einen raschen Prozess der ,Autoromanisation“ von der protohistorischen zur historischen Epoche, wobei aber im Ergebnis die beharrenden Elemente nicht übersehen werden sollten. Aufs Ganze gesehen haben wir es hier anders als nach derzeitigem Forschungsstand in weiten Bereichen des Oberrheins weniger mit einem Bruch zwischen Spätlatène D 2 und augusteischer Epoche zu tun als mit einem evolutionären Prozess. Angebracht ist an dieser Stelle auch ein Hinweis auf das nahezu gänzliche Fehlen archäologischer Fundorte in der elsässischen Ebene, die für die augusteische Zeit charakteristisch sind. Nur wenige Siedlungen weisen Spuren von Romanisierung aus der Zeit vor Tiberius auf, aber hier gilt es die Ergebnisse weiterer Forschungen, die etwa in Brumath, dem Hauptort der Triboker, derzeit laufen, abzuwarten. Im ländlichen Raum ist eine Siedlungskontinuität von der spätkeltischen in die römische Zeit zu beobachten, aber ohne gravierende Veränderungen in der materiellen Kultur. An anderer Stelle entstanden Römerstädte gleichsam ex nihilo ähnlich wie etwa in Trier oder Waldgirmes oder waren sowohl Folge als auch Voraussetzung für die Stationierung römischer Truppen. Zweifellos muss mit unterschiedlichen Modellen und unterschiedlicher Abfolge von Urbanisierung und ErschlieBung durch vici, villae oder Streusiedlungen gerechnet werden und damit auch mit unterschiedlicher Intensität von Romanisation, die auch ein eigenständiges Tertium zwischen indigener und mittelmeerländischer Kultur und Zivilisation zur Folge haben kann. In kleinerem Maßstab gilt das auch für die historischen Prozesse in den Oberrheinlanden in dem von uns hier betrachteten Zeitrahmen.

In nachcaesarischer Zeit lässt sich ein verstärktes militärisches Engagement Roms zunächst eher im rückwärtigen Bereich der Rheinfront nachweisen. Die allgemeine Entwicklung geht einher mit einem Bedeutungsverlust der Rheinachse zugunsten der Achse Rhône-Saône-Obermosel und Konsolidierung des innergallischen Wirtschaftsraumes durch stärkere Anbindung an die Gallia Transalpina bzw. Narbonensis. Ein erster Ausbau des Fernstraßennetzes wurde begleitet von frühen Militäranlagen wie auf dem Titelberg in Luxemburg oder dem Petrisberg in Trier. Auf dem Titelberg setzte sich das römische Militär in ein mächtiges keltisches Oppidum der Treverer mit einem bedeutenden Heiligtum und starker Umwehrung mittels eines murus Gallicus. Die Anlage auf dem Petrisberg diente zweifellos dem Schutz der wichtigen Römerstraße, die hier über die Mosel führte. Beide Maßnahmen mögen im Zusammenhang mit einem Aufstand der Treverer 30/29 v. Chr. stehen. Die Überwachung der eroberten Gebiete Roms und des Vorfeldes durch die Übersiedlung germanischer Stammesverbände auf linksrheinisches Gebiet, ferner durch Stationierung römischer Legionäre oder auxiliarii in einheimischen oppida unter Nutzung auch der dortigen Bewohner für diesen Zweck scheint bis in augusteische Zeit reichende Epoche typisch zu sein und ist zeitweise auch 
an Ober- und Hochrhein nachweisbar. Hier existierten zeitgleich immer noch einige größere latènezeitliche Siedlungen, so wahrscheinlich in Altenburg-Rheinau am Hochrhein bis zur Anlage des Legionslagers Dangstetten, was im Zusammenhang mit den Alpenfeldzügen 15 v. Chr. erfolgte, oder in Basel-Münsterhügel, wo zwar eine einheimische Siedlung fortbestand, in der aber ähnlich wie in Vindonissa anscheinend eine kleine Abteilung römischer Truppen ab 30/25 v. Chr. stationiert war. ${ }^{52}$ Der Ort verlor aber schon bald seinen militärischen Charakter. Erst in frühtiberischer Zeit setzt mit Errichtung der Legionslager in Vindonissa und Argentorate sowie weiterer Kastelle und militärischer Anlagen an Hoch- und Oberrhein eine systematischere militärische Sicherung ein, ${ }^{53}$ mit der aber Hand in Hand eine markante, von Rom geduldete oder gar geförderte zivile Aufsiedlung und Erschließung von Räumen ging, die längere Zeit weitgehend siedlungsleer waren. Das Gefährdungspotential an diesem Grenzabschnitt des Imperiums war jedenfalls ein anderes als in Niedergermanien, und spätestens seit Vespasian waren Hoch- und Oberrhein ein Binnenland in Obergermanien. Nicht von ungefähr war die Legion in Straßburg bereits $43 \mathrm{n}$. Chr. zum Britannienfeldzug abgezogen worden; erst in domitianischer Zeit, also ca. 40 Jahre später, wurde hier wieder eine Legion stationiert. Irritierend ist, dass wir über die frühkaiserzeitlichen Verhältnisse im Raum um Worms, dem Hauptsitz der Vangionen, und um Speyer, dem Hauptsitz der Nemeter, so schlecht unterrichtet sind. Nur vermutungsweise und aufgrund vor allem von Funden frühkaiserzeitlicher Grabsteine von Auxiliarsoldaten an diesen Orten ist davon auszugehen, dass hier zumindest ab tiberischer Zeit, aber wohl kaum früher, befestigte Wehranlagen bestanden.

Ein vergleichender Blick auf die Karte des gesamten Imperium Romanum dürfte verdeutlichen, mit welch einem begrenzten zeitlichen und räumlichen Abschnitt eines einstigen Weltreichs wir uns hier beschäftigt haben, der dennoch auch überregionale Prozesse erkennen lässt. Die literarische Überlieferung stellt gleichsam das Tableau bereit, das mittels der aus anderen Quellen gewonnenen Erkenntnisse Farbe und geschärfte Konturen erhält. Angesichts der nach wie vor bestehenden Kontroversen dürfte jedoch der Stoff für weitere Forschungen, Thesen und Hypothesen in allen Quellenbereichen für unabsehbare Zeit nicht ausgehen.

\footnotetext{
${ }^{52}$ S. u. a. DesChLER-ERB 2004; DESCHLER-ERB/HAGENDORN 2005; DESCHLER-ERB 2008.

53 Jüngst erneut betont von REDDÉ 2015, 300-306 mit Verweis auf die frühere Literatur insbesondere zu Argentorate/Straßburg. - Zu Vindonissa s. bes. HAGENDORN (HG.) 2003 und VINDONISSA 2003, 464 f. Ferner REDDÉ 2009, 408 mit weiterer Literatur in Anm. 21. Zu den Truppen des Windischer Heeresverbandes HARTMANN/SPEIDEL 1991.
} 


\section{Literaturverzeichnis}

ASSKAMP 1989 = R. Asskamp, Das südliche Oberrheingebiet in frührömischer Zeit (Stuttgart 1989).

Bender/Pohl 2005 = H. Bender/G. Pohl, Der Münsterberg in Breisach, I: Römische Zeit und Frühmittelalter. Karolingisch-vorstaufische Zeit. Münchner Beitr. Voru. Frühgesch. 39 (München 2005).

BLÖCK 2016 = L. Blöck, Die römerzeitliche Besiedlung im rechten südlichen Oberrheingebiet. Forsch. u. Ber. zur Arch. Baden- Württemberg 1 (Esslingen 2016).

BlÖCK/LAUBER/TRÄNKLE 2016 = L. Blöck/J. Lauber/Fl. Tränkle, Princeps Sueborum Der $>>$ Neufund $<<$ einer römischen Grabinschrift aus Offenburg-Bühl (Ortenaukreis). Arch. Korrbl. 46, 2016, 497-516.

BRÄUNING 2005 = A. Bräuning, Das Doppeloppidum Altenburg-Rheinau, Gem. Jestetten, Kreis Waldshut (D); Rheinau, Kanton Zürich (CH), in: Kelten 2005 (s. dort) 72-78.

Dangstetten I-III 1986/2011 = G. Fingerlin, Dangstetten I und II. Kataloge der Fundstellen 1-603 und 604-1358; K. Roth-Rubi, Dangstetten III. Das Tafelgeschirr aus dem Militärlager von Dangstetten (Stuttgart 1986/2006).

DEHN $2005=$ R. Dehn, Das Oppidum Tarodunum bei Kirchzarten, Kreis BreisgauHochschwarzwald, in: Kelten 2005 (s. dort) 86-89.

Deschler-Erb u.a. 1991 = E. Deschler-Erb/M. Peter/S. Deschler-Erb, Das frühkaiserzeitliche Militärlager in der Kaiseraugster Unterstadt. Forschungen in Augst 12 (Augst 1991).

DESCHLER-ERB 1999 = E. Deschler-Erb, Ad arma! Römisches Militär des 1. Jahrhunderts n. Chr. in Augusta Raurica. Forschungen in Augst 28 (Augst 1999).

DESCHLER-ERB 2004 = E. Deschler-Erb, Basel-Münsterhügel. Überlegungen zur Chronologie im 1. Jahrhundert v. Chr., in: Hüssen/Irlinger/Zanier (Hg.) 2004 (s. dort) 149-164.

DESCHLER-ERB/HAGENDORN 2005 = E. Deschler-Erb/A. Hagendorn, Die spätkeltische Siedlung auf dem Basler Münsterhügel, in: Kelten 2005 (s. dort) 113-120.

DESCHLER-ERB 2008 = E. Deschler-Erb, Basel-Münsterhügel am Übergang von spätkeltischer zur römischen Zeit - Ein Beispiel für die Romanisierung im Nordosten Galliens (Zürich 2008).

DREIER $2005=$ Chr. Dreier, Riegel am Kaiserstuhl - Militärlager und mutmaßlicher Civitashauptort, in: Planck (Hg.) 2005 (s. dort) 273-278.

ECKERLE/FINGERLIN $2005=$ Kl. Eckerle/ G. Fingerlin, Hüfingen, in: Planck (Hg.) 2005 (s. dort) 127-133.

FERDIÈRE 2005 = A. Ferdière, Les Gaules, II ${ }^{\mathrm{e}}$ siècle av. J.-C. $-\mathrm{V}^{\mathrm{e}}$ siècle ap. J.-C. (Paris 2005).

FICHTL $2000=$ St. Fichtl, Le Rhin supérieur de moyen du II ${ }^{\mathrm{e}}$ siècle av. J.-C. à la fin du $\mathrm{I}^{\mathrm{er}}$ siècle av. J.-C. Quelque réflexions historiques sur les questions du peuplements. Germania 78, 2000, 1-28. 
FICHTL 2004 = St. Fichtl, L'oppidum du Fossé des Pandours, le chef-lieux des Médipomatriques à l'époque de l'indépendance?, in: St. Fichtl (Hg.), Les oppida du nord-est de la Gaule à la Tène finale. Archeologia Mosellana 5 (Luxembourg 2004) 145-160.

FichtL/PIERREVELCIN $2005=$ St. Fichtl/ G. Pierrevelcin, Nouveaux éléments pour une chronologie de l'oppidum du fossé des Pandours au col de Saverne (Bas.Rhin), in: St. Fichtl (Hg.), Hiérarchie de l'habitat rural dans le Nord-Est de la Gaule à la Téne moyenne et finale. Archaeologia Mosellana 6 (Luxembourg 2005) 417-438.

FILTZINGER $1986=\mathrm{Ph}$. Filtzinger, Die römische Besetzung Baden-Württembergs, in: Ders./D.Plack/B.Cämmerer (Hg.), Die Römer in Baden-Württemberg (Stuttgart 31986) 23-116.

FINGERLIN $1973=$ G. Fingerlin, Keltenstadt und Römerlager. Der Limberg bei Sasbach (I). Arch. Nachr. Baden 10, 1973, 5-9.

FINGERLIN $1975=$ G. Fingerlin, Keltenstadt und Römerlager. Der Limberg bei Sasbach (II). Arch. Nachr. Baden 15, 1975, 9-15.

FINGERLIN $2006=$ G. Fingerlin, Vom Oberrhein zur jungen Donau. Die Straße durch den südlichen Schwarzwald in keltischer, römischer und frühmittelalterlicher Zeit. Arch. Nachr. Baden 72/73, 2006, 62-72.

FISCHER 1988 = Fr. Fischer, Südwestdeutschland im letzten Jahrhundert vor Christi Geburt, in: D. Planck (Hg.), Archäologie in Württemberg (Stuttgart 1988) 235-250.

FISCHER 2004 = Fr. Fischer, Das Oppidum bei Altenburg-Rheinau und sein spätlatènezeitliches Umfeld, in: Hüssen/Irlinger/Zanier (Hg.) 2004 (s. dort) 123-132.

FISCHER $2006=$ Fr. Fischer, Zur frühen Geschichte am Oberrhein. Arch. Nachr. Baden 72/73, 2006, 53-59.

FORRER $1927=$ R. Forrer, Strasbourg - Argentorate, 2 Bde. (Strasbourg 1927).

FORRER $1935=\mathrm{R}$. Forrer, L'Alsace romaine (Paris 1935).

GoudinEAU 1996 = C. Goudineau, Gaul, in: CAH X: The Augustan Empire 43 BC-AD 49 (Cambridge 1996) 464-502.

HÄNGGi/Doswald/Roth-Rubi 1994 = R. Hänggi/C. Doswals/K. Roth-Rubi, Die frühen römischen Kastelle und der Kastellvicus von Tenedo-Zurzach. Veröffentl. Ges. Pro Vindonissa 11 (Brugg 1994).

HAGENDORN (Hg.) 2003 = A. Hagendorn (Hg.), Zur Frühzeit von Vindonissa. Auswertung der Holzbauten der Grabung Windisch-Breite 1996-1998. Veröffentl. Ges. Pro Vindonissa 18 (Brugg 2003).

HARTMAnN/SPeIDEL 1991 = M. Hartmann/M. A. Speidel, Die Hilfstruppen des Windischer Heeresverbandes. Zur Besetzungsgeschichte von Vindonissa im 1. Jahrhundert n. Chr. Jahresber. Ges. Pro Vindonissa 1991, 3-33.

HATT 1978 = J.-J. Hatt, L'Alsace celtique et romain, 2200 av. J.-C à 450 ap. J.-C. (Wettolsheim 1978).

HATt 1980 = J.-J. Hatt, Strasbourg romain, in: G. Livet/F. Rapp (Hg.), Histoire de Strasbourg des origines à nos jours (Strasbourg 1980) 75-284. 
HÜSSEN/IRLINGER/ZANIER (Hg.) 2004 = C.-M. Hüssen/W. Irlinger/W. Zanier (Hg.), Spätlatènezeit und frühe römische Kaiserzeit zwischen Alpenrand und Donau. Akten des Colloquiums in Ingolstadt am 11. und 12. Oktober 2001 Kolloquien zur Vor- und Frühgeschichte 8 (Bonn 2004).

Kelten 2005 = A. Bräuning u. a., Kelten an Hoch- und Oberrhein. Führer arch. Denkmäler Baden-Württemberg 24 (Esslingen 2005).

MATIJEVIĆ 2008 = K. Matijević, Beobachtungen zur Gründung von Lugudunum/Lyon. Gymnasium 115, 2008, 141-168.

MAYER-REPPERT 2003 = P. Mayer-Reppert, Römische Funde aus Konstanz. Vom Siedlungsbeginn bis zur Mitte des 3. Jahrhunderts n. Chr. Fundber. Baden-Württemberg 27, 2003, 441-554.

Murer/Roth-Zehner 2009 = A. Murer/ M. Roth-Zehner, Le sud de la pleine du Rhin supérieur entre militaires romains et indigènes rauraques à travers l'example du vicus de Sierentz, in: Société francaise d'étude de la céramique antique en Gaule. Actes du congrès de Colmar, 21-24 mai 2009 (Marseille 2009) 133-148.

Nesselhauf $1951=\mathrm{H}$. Nesselhauf, Die Besiedlung der Oberrheinlande in römischer Zeit. Badische Fundberichte 19, 1951, 71-85 (= Ndr. in: E. Schwarz [Hg.], Zur germanischen Stammeskunde. Aufsätze zum neuen Forschungsstand, WdF 249 [Darmstadt 1972] 123-145).

NIERHAUS $1966=$ R. Nierhaus, Das swebische Gräberfeld von Diersheim. Studien zur Geschichte der Germanen am Oberrhein vom Gallischen Krieg bis zur alamannischen Landnahme (Berlin 1966).

NÜSSE/MARX/LELGEMANN 2011 = H.-J. Nüsse/Chr. Marx/D. Lelgemann, Germania magna - ein neuer Blick auf eine alte Karte. Entzerrte geographische Daten für die antiken Orte zwischen Rhein und Weichsel. Germania 89, 2011, 115-155.

PlancK (Hg.) 2005 = D. Planck (Hg.), Die Römer in Baden-Württemberg (Stuttgart 2005).

REDDÉ $2005=$ M. Reddé, Ou sont passés les castella Drusiana? Reflexions critiques sur les débuts de l'occupation militaire romaine dans le basin du Rhin supérieur. REMA 2, 2005 (2008) 69-87.

REDDÉ 2009 = M. Reddé, Oedenburg et l'occupation militaire romaine sur le Rhin supérieur. In: Ders. (Hg.), Oedenburg - Fouilles françaises, allemandes et suisses à Biesheim et Kunheim (Haut-Rhin), I: Les camps militaires julio-claudiens. Monographien RGZM 79/1 (Mainz 2009) 403-428.

REDDÉ 2015 = M. Reddé, Befunde und Erkenntnisse zu den römischen Militäranlagen am Oberrhein in augusteischer und tiberischer Zeit, in: G. A. Lehmann/R. Wiegels (Hg.), Über die Alpen und über den Rhein. Beiträge zu den Anfängen und zum Verlauf der römischen Expansion nach Mitteleuropa. Abhandlg. Akad der Wiss zu Göttingen, N. F. 37 (Berlin/Boston 2015) 299-311.

ROTH-ZEHNER $2005=$ M. Roth-Zehner, L'habitat rural dans la pleine d'Alsace à la Tene finale. Archaeologia Mosellana 6 (Luxembourg 2005) 219-232.

ROTH-ZEHNER $2010=$ M. Roth-Zehner, Les établissements ruraux de la Tène finale dans la pleine d'Alsace. Etat de la question. Cahiers alsaciens d'archéologie, d'art et d'histoire 53, 2010, 31-62. 
SCHÖNBERGER $1985=$ H. Schönberger, Die römischen Truppenlager der frühen und mittleren Kaiserzeit zwischen Nordsee und Inn. Ber. RGK 66, 1985, 321-407.

SCHLEGEL $2000=$ O. Schlegel, Germanen im Quadrat: Die Neckarsweben im Gebiet von Mannheim, Ladenburg und Heidelberg während der frühen römischen Kaiserzeit (Rahden/Westf. 2000).

SCHREMPP U. A. 2015 (2016) = J. Schrempp/M. Machura/J. Lauber/K. Kortüm/A. Heising, Frühe Germanen am Oberrhein? Ein neues Gräberfeld mit Waffenbeigaben in Diersheim. Arch. Ausgr. Baden-Württemberg 2015 (2016) 158-161.

SchrEMPP U.A. 2016 (2017) = J. Schrempp/A. Heising/J. Lauber/K.Kortüm, Diersheims „Sueben“ - Zeugen tiberischer Grenzpolitik am Oberrhein, Arch. Ausgr. Baden-Württemberg 2016 (2017) 176-179.

STORK 2007 = I. Stork, Die spätkeltische Siedlung von Breisach-Hochstetten. Forsch. u. Ber. Vor- u. Frühgesch. Baden-Württemberg 102 (Stuttgart 2007).

TIMPE 1975 = D. Timpe, Zur Geschichte der Rheingrenze zwischen Caesar und Drusus, in: E. Lefèvre (Hg.), Monumentum Chiloniense. Studien zur augusteischen Zeit. Kieler Festschrift f. E. Burck zum 70. Geburtstag (Amsterdam 1975) 124-14 (= Ndr. in: D. Timpe, Römisch-germanische Begegnung in der späten Republik und frühen Kaiserzeit. Voraussetzungen - Konfrontationen - Wirkungen. Gesammelte Schriften. Beitr. z. Altertumskunde 233 (München-Leipzig 2006) 147-170.

TIMPE $1998=$ D. Timpe, Germanen, in: Germanen, Germania, Germanische Altertumskunde - Studienausgabe. RGA ${ }^{2}$ (Berlin/New York 1998) 1-65.

VINDONISSA 2003 = A. Hagendorn u. a., Zur Frühzeit von Vindonissa. Auswertung der Holzbauten der Grabung Windisch-Breite 1996-1998. Veröffentl. Ges. Pro Vindonissa 18 (Brugg 2003).

WAGNER 1908/1911 = E. Wagner, Fundstätten und Funde aus vorgeschichtlicher, römischer und alamannisch-fränkischer Zeit im Großherzogthum Baden, 2 Bde. (Tübingen 1908/1911).

WALSER 1956 = G. Walser, Caesar und die Germanen. Historia-Einzelschriften 1 (Wiesbaden 1956).

WALSER 1998 = G. Walser, Bellum Helveticum: Studien zum Beginn der caesarischen Eroberung von Gallien. Historia-Einzelschriften 118 (Stuttgart 1998).

WEBER-JENISCH 1995 = G. Weber-Jenisch, Der Limberg bei Sasbach und die spätlatènezeitliche Besiedlung des Oberrheingebietes. Materialhefte zur Arch. in Baden-Württemberg (Stuttgart 1995).

WendLing $2004=\mathrm{H}$. Wendling, Neues aus Tarodunum. Ausgrabungen in der mittelund spätlatènezeitlichen Großsiedlung von Kirchzarten-Zarten „Rotäcker“, Kreis Breisgau-Hochschwarzwald. Arch. Ausgr. Baden-Württemberg 2004 (2005) 102-110.

WendLing 2005/1 = H. Wendling, Breisach am Rhein. Siedlungen in Hochstetten und auf dem Münsterberg, Kreis Breisgau-Hochschwarzwald, in: Kelten 2005 (s. dort) 79-82.

WendLing 2005/2 = H. Wendling, Sasbach am Kaiserstuhl. Siedlungen auf und im Umfeld des Limberges, Kreis Emmendingen, in: Kelten 2005 (s. dort) 97-99. 
WendLING 2005/3 = H. Wendling, Töpfer, Schmiede, Münzmeister. Nachweise spätkeltischen Handwerks in Tarodunum, Gde. Kirchzarten, Kreis Breisgau-Hochschwarzwald. Arch. Ausgr. Baden-Württemberg 2005 (2006) 107-110.

WENDLING $2006=\mathrm{H}$. Wendling, Zur spätlatènezeitlichen Besiedlung auf dem Breisacher Münsterberg, Arch. Nachr. Baden 72/73, 2006, 23-31.

WENDLING $2007=$ H. Wendling, Die Spätlatènezeit auf dem Münsterberg von Breisach . Neueste Untersuchungen zur Chronologie und Chorologie eines oberrheinischen Zentralortes, in: Ph. Barral u.a. (Hg.), L'âge du Fer dans l'arc jurassien et ses marges. Dépots, lieux sacrés et territorialité à l'âge du Fer. Actes du XXIXe colloque intern. de l'AFEAF Bienne, 5-8 mai 2005 (Besançon 2007) 119-137.

WIEGELS $1981=$ R. Wiegels, Numerus exploratorum Tribocorum et Boiorum, in: Epigraphische Studien 12 (Köln/Bonn 1981) 309-331.

WIEGELS $1983=\mathrm{R}$. Wiegels, Zeugnisse der 21. Legion aus dem südlichen und mittleren Oberrheingebiet. Zur Geschichte des obergermanischen Heeres um die Mitte des 1. Jahrhunderts n. Chr., in: Epigraphische Studien 13 (Köln/Bonn 1983) 1-43.

WIELAND 1996 = G. Wieland, Die Spätlatènezeit in Württemberg. Forsch. u. Ber. zur Vor- u. Frühgesch. Baden-Württemberg 63 (Stuttgart 1996).

WOLF 2005 = J.-J. Wolf, Eine spätlatènezeitliche Siedlung in Sierentz, in: Kelten 2005 (s.dort) 100-104.

ZANIER $2004=$ W. Zanier, Gedanken zur Besiedlung der Spätlatène- und frühen römischen Kaiserzeit zwischen Alpenrand und Donau. Eine Zusammenfassung mit Ausblick und Fundstellenlisten, in: Hüssen/Irlinger/Zanier (Hg.) 2004 (s. dort) 237-264.

ZEHNER $2010=$ M. Zehner, La céramique de la Tène finale et du début de l'époque romaine en Alsace. Thèse Univ. Strasbourg (Strasbourg 2010). 


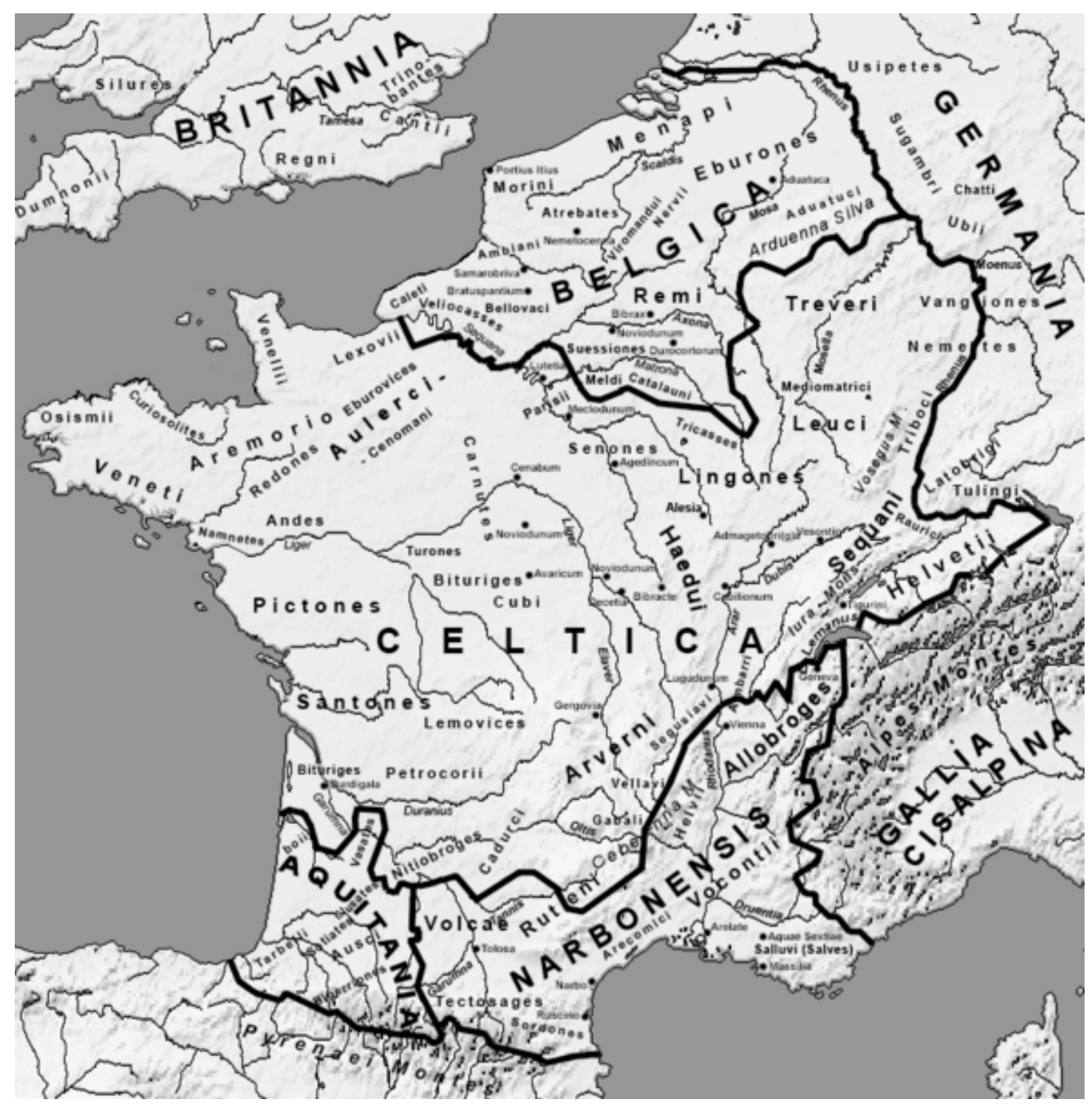

Abb. 1 Gallien zur Zeit Caesars - Stammesgebiete (C) Feitscherg CC BY-SA 3.0) 
Frankfurter elektronische Rundschau zur Altertumskunde 34 (2017)

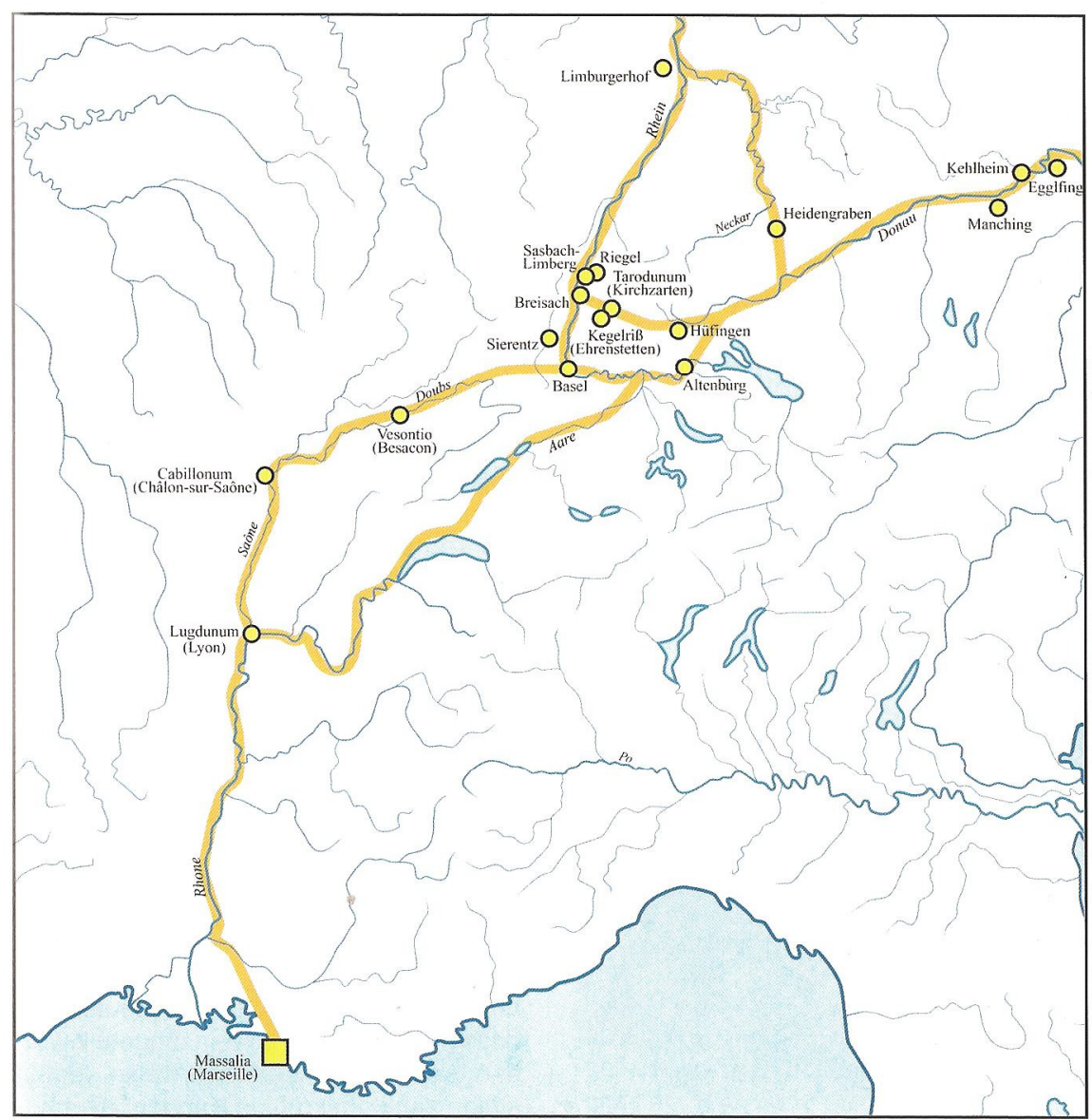

Abb. 2 Hauptverkehrsweg zwischen Massilia und Hoch- und Oberrhein (nach Kelten 2005, Abb. 44 [M. Nick])

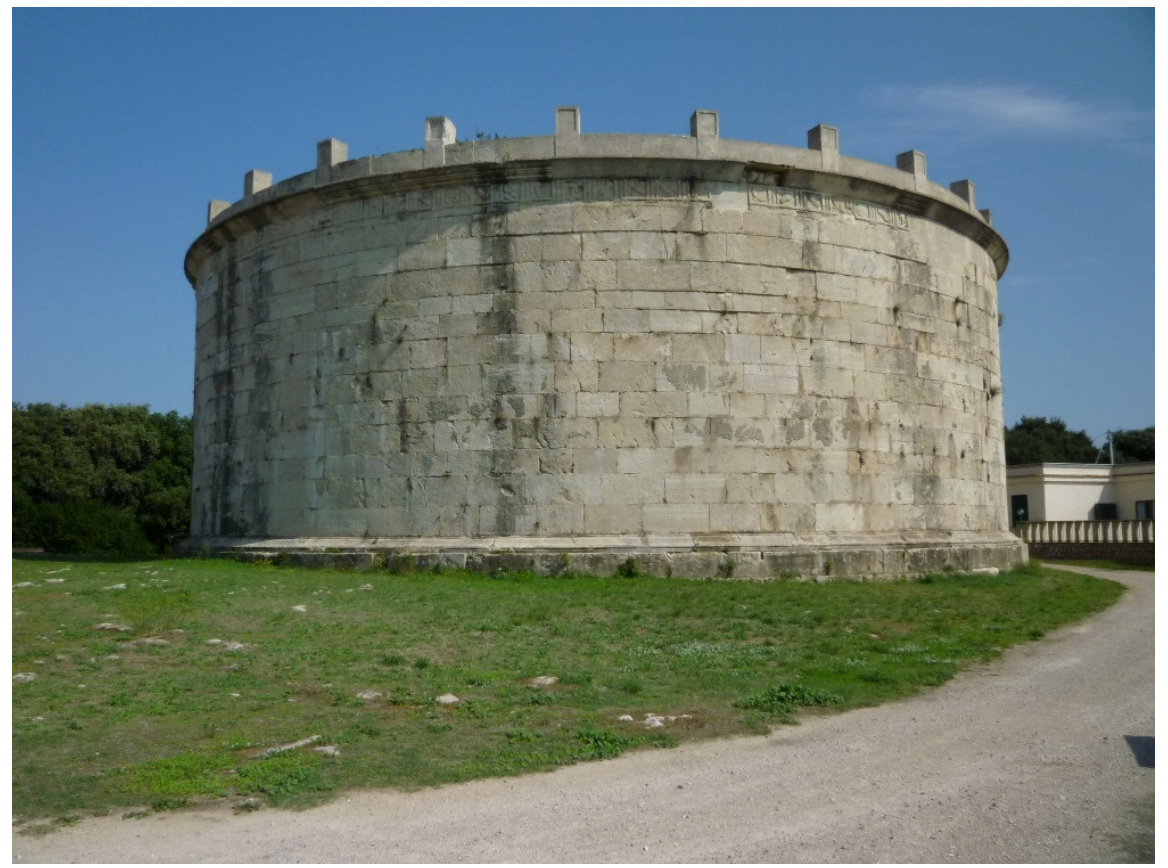

Abb. 3a Gaëta (Italien) - Grabmal des L. Munatius Plancus 
Frankfurter elektronische Rundschau zur Altertumskunde 34 (2017)

(C) A. Ardetti-CC BY-SA 2.0 fr.)

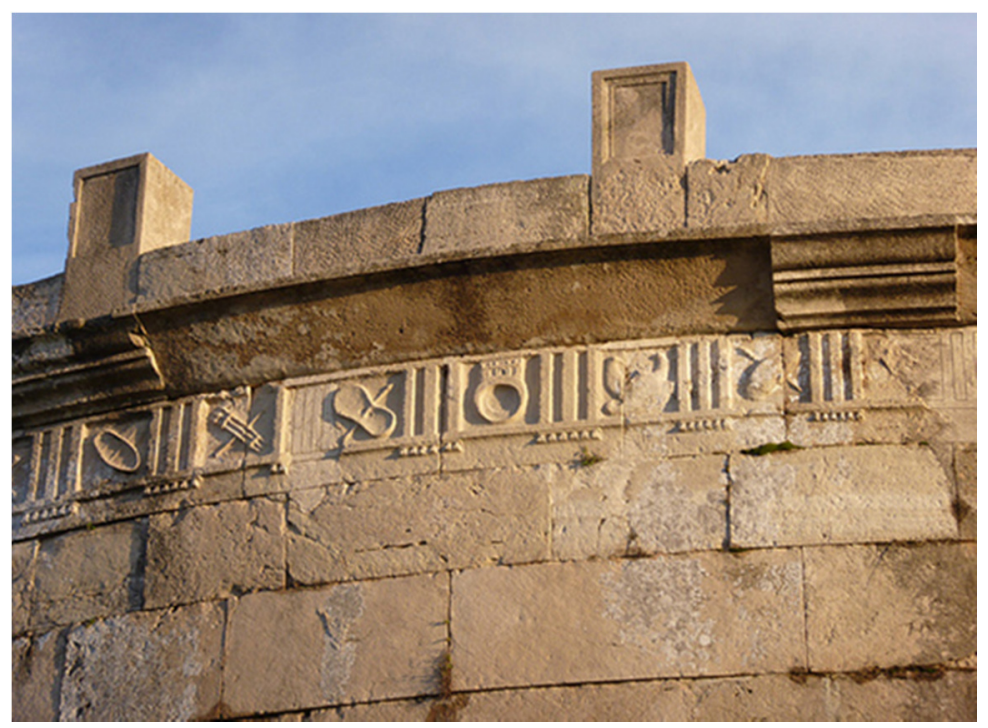

Abb. 3b Gaëta (Italien) - Grabmal des L. Munatius Plancus - Waffenfries (R. Wiegels)

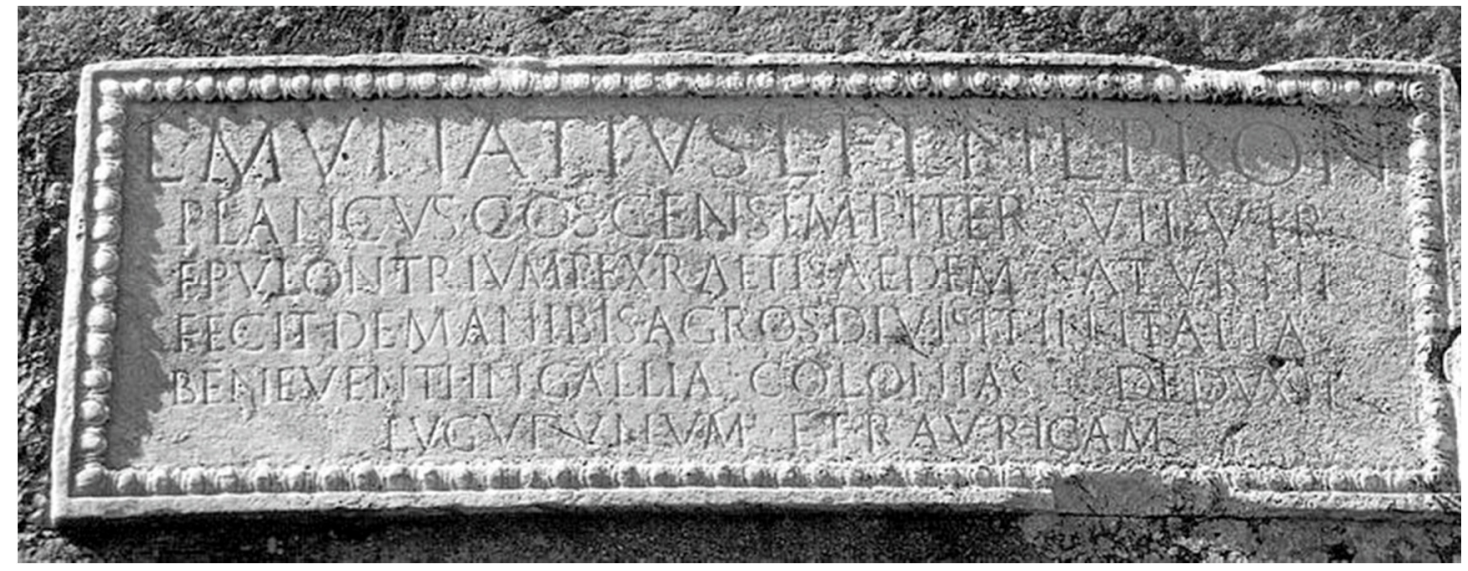

Abb. 3c Gaëta (Italien) - Grabinschrift des L. Munatius Plancus (CIL XIII Photodatei Flensburg/Trier) 
Frankfurter elektronische Rundschau zur Altertumskunde 34 (2017)
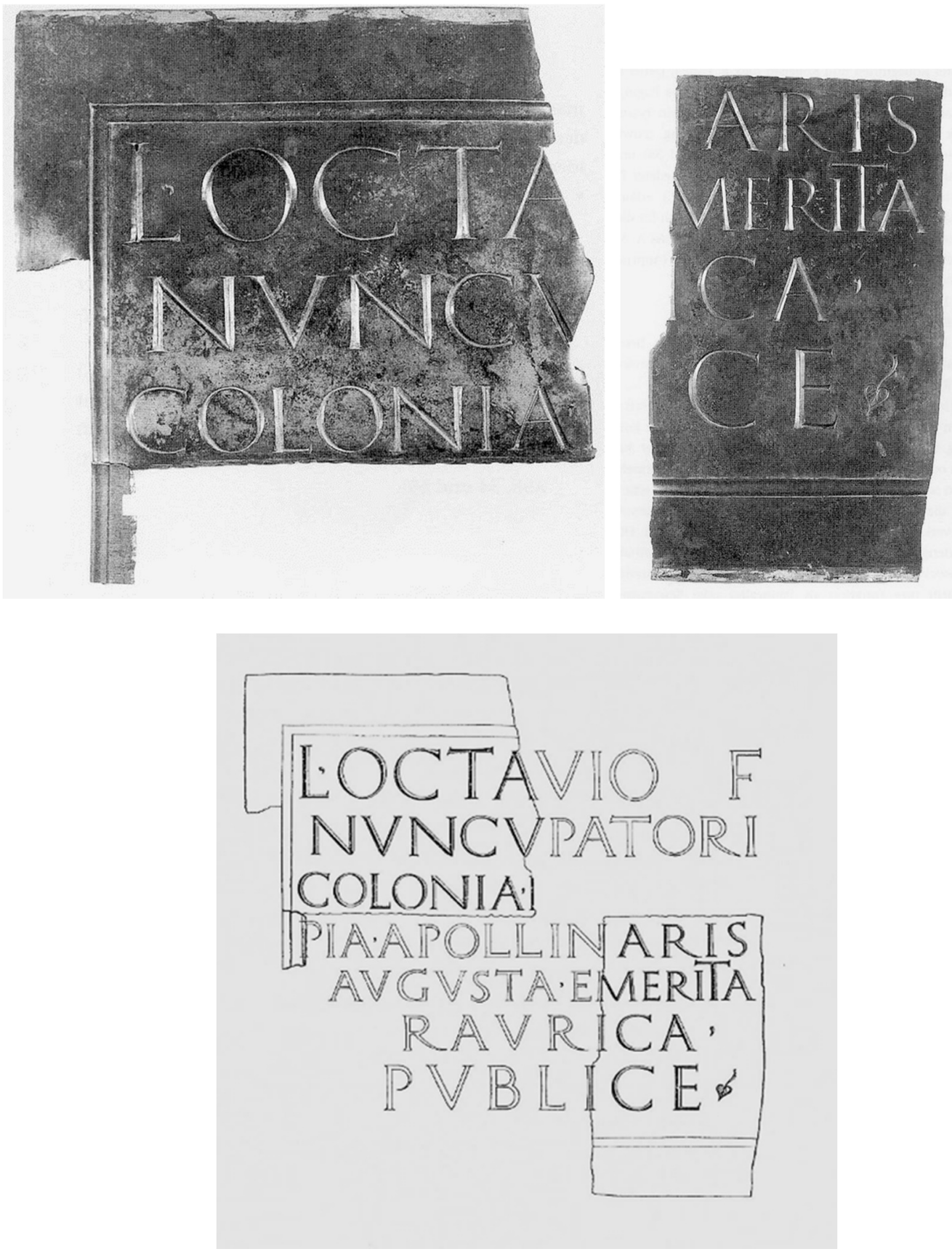

Abb. 4 Augst (CH) - Bronzetafel(n) - Ehreninschrift für Octavius mit Rekonstruktion (CIL XIII Photodatei Flensburg/Trier) 
Frankfurter elektronische Rundschau zur Altertumskunde 34 (2017)

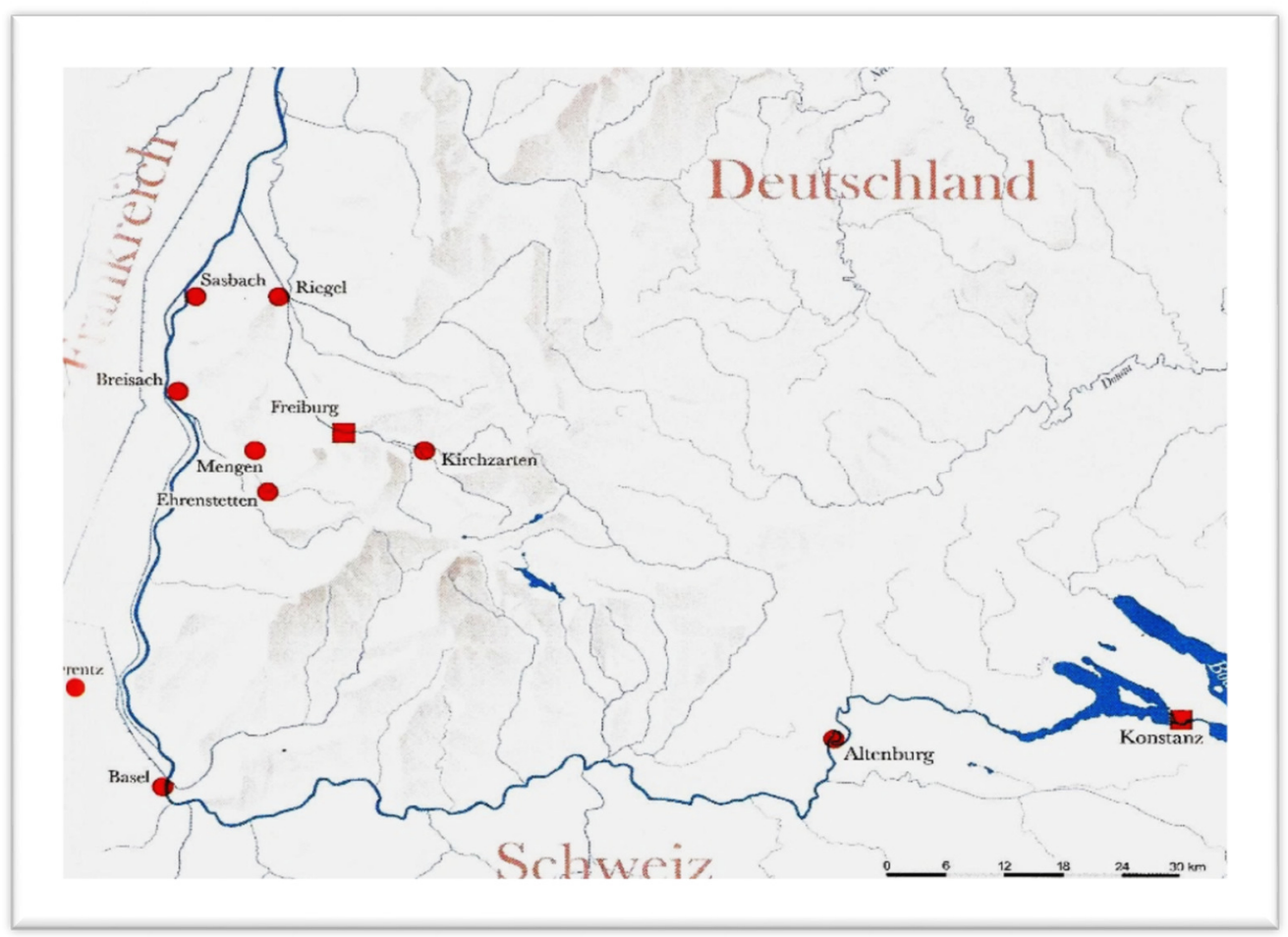

Abb. 5 Zentrale spätlatènezeitliche Siedlungen an Hoch- und Oberrhein (nach Kelten 2005, 9)

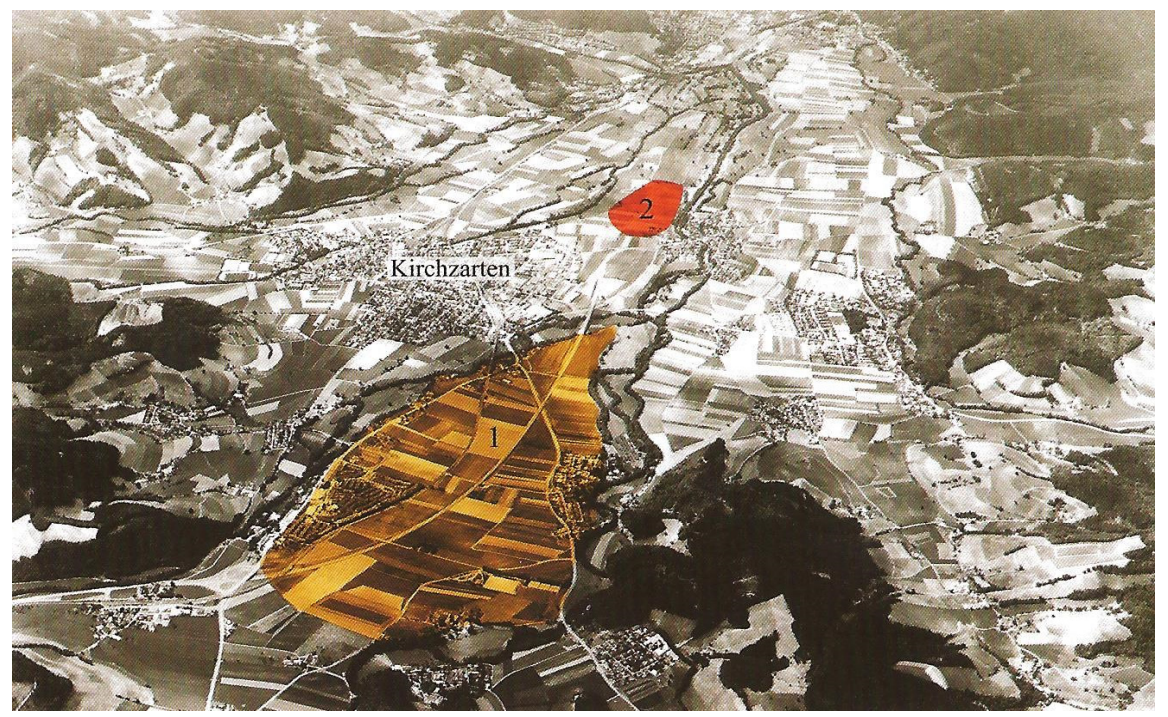

Abb. 6 Tarodunum/Zarten u. Kirchzarten - Spätkeltisches Oppidum (nach Kelten 2005, Abb. 95 [Referat Denkmalpflege RP Freiburg]) 
Frankfurter elektronische Rundschau zur Altertumskunde 34 (2017)

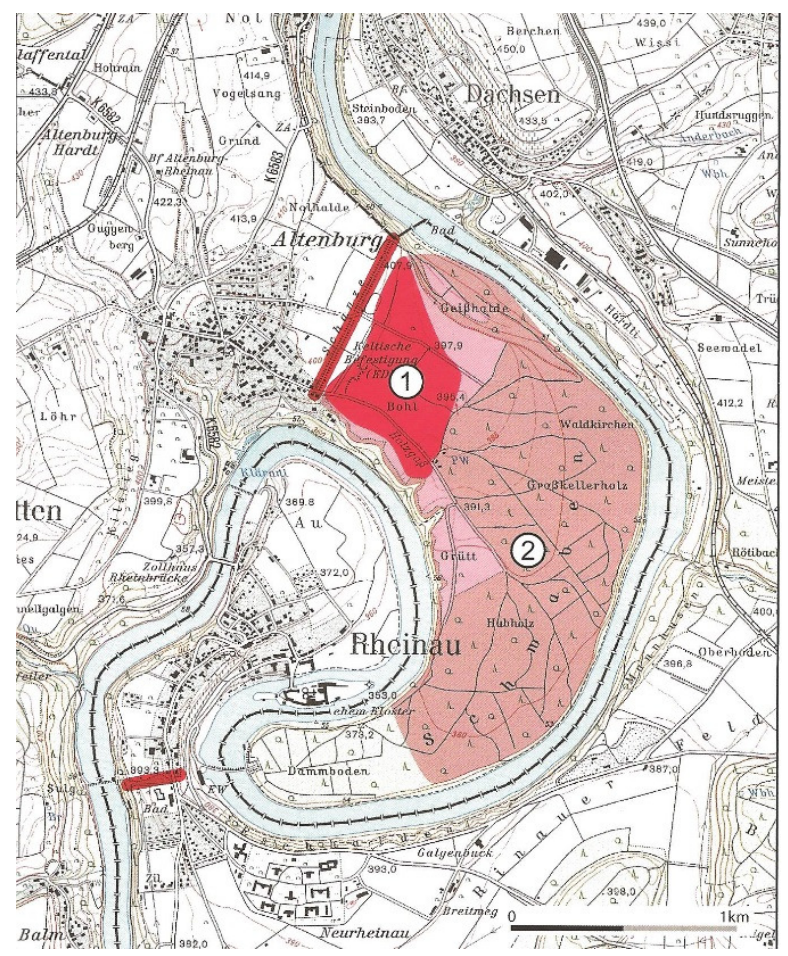

Abb. 7 Altenburg-Rheinau (D / CH) Plan der Siedlung (nach Kelten 2005, Abb. 78 [Referat Denkmalpflege RP Freiburg])

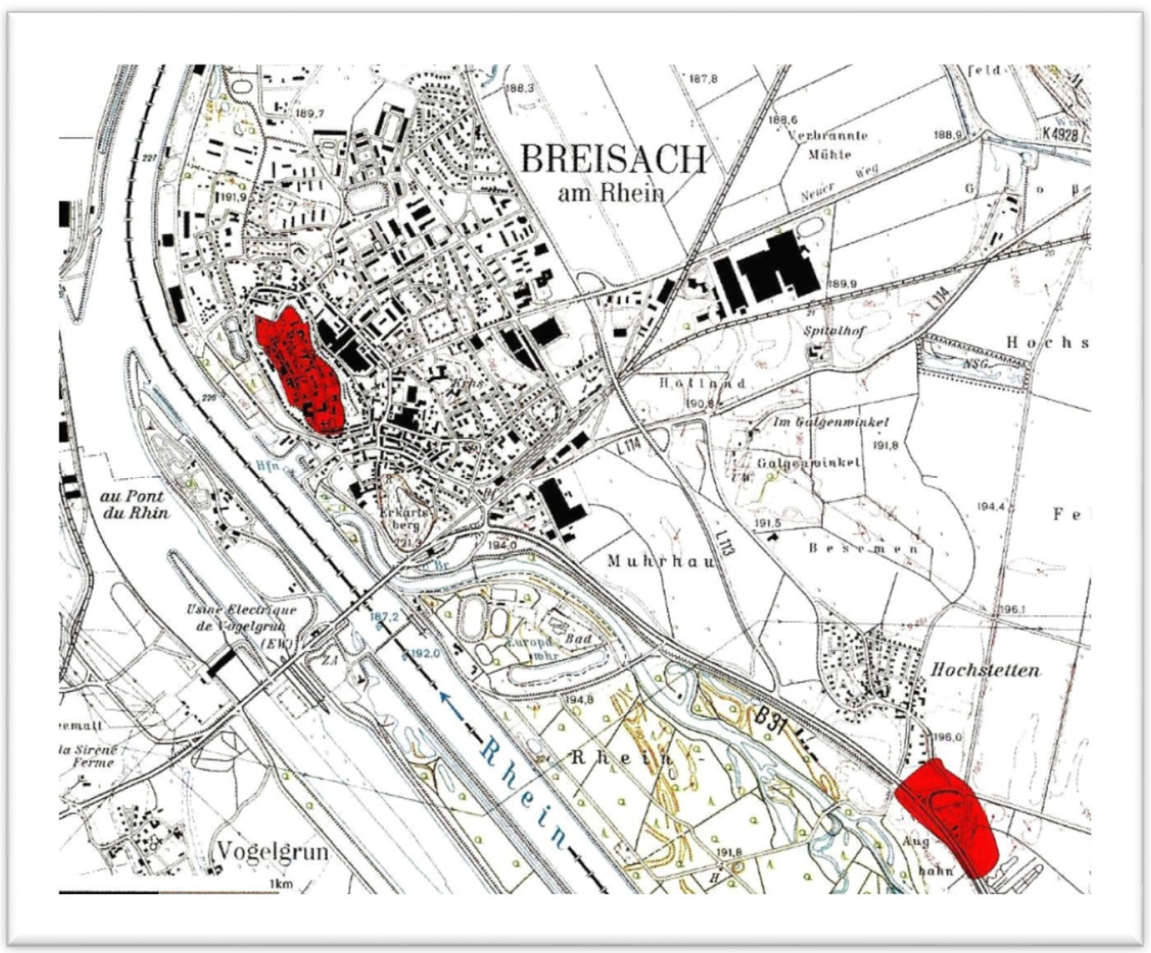

Abb. 8 Breisach-Münsterberg und Breisach-Hochstetten (nach Kelten 2005, Abb. 87 [Referat Denkmalpflege RP Freiburg]) 
Frankfurter elektronische Rundschau zur Altertumskunde 34 (2017)

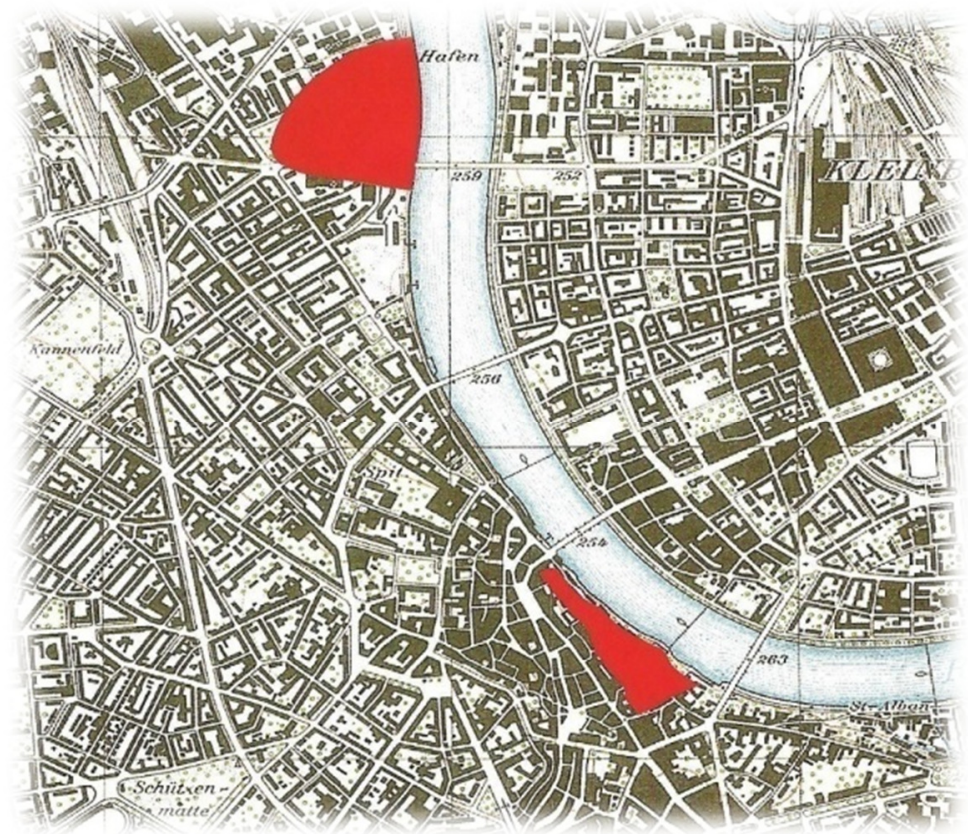

Abb. 9 Basel-Munsterberg und Basel-Gasfabrik (CH) (nach Kelten 2005, Abb. 120)

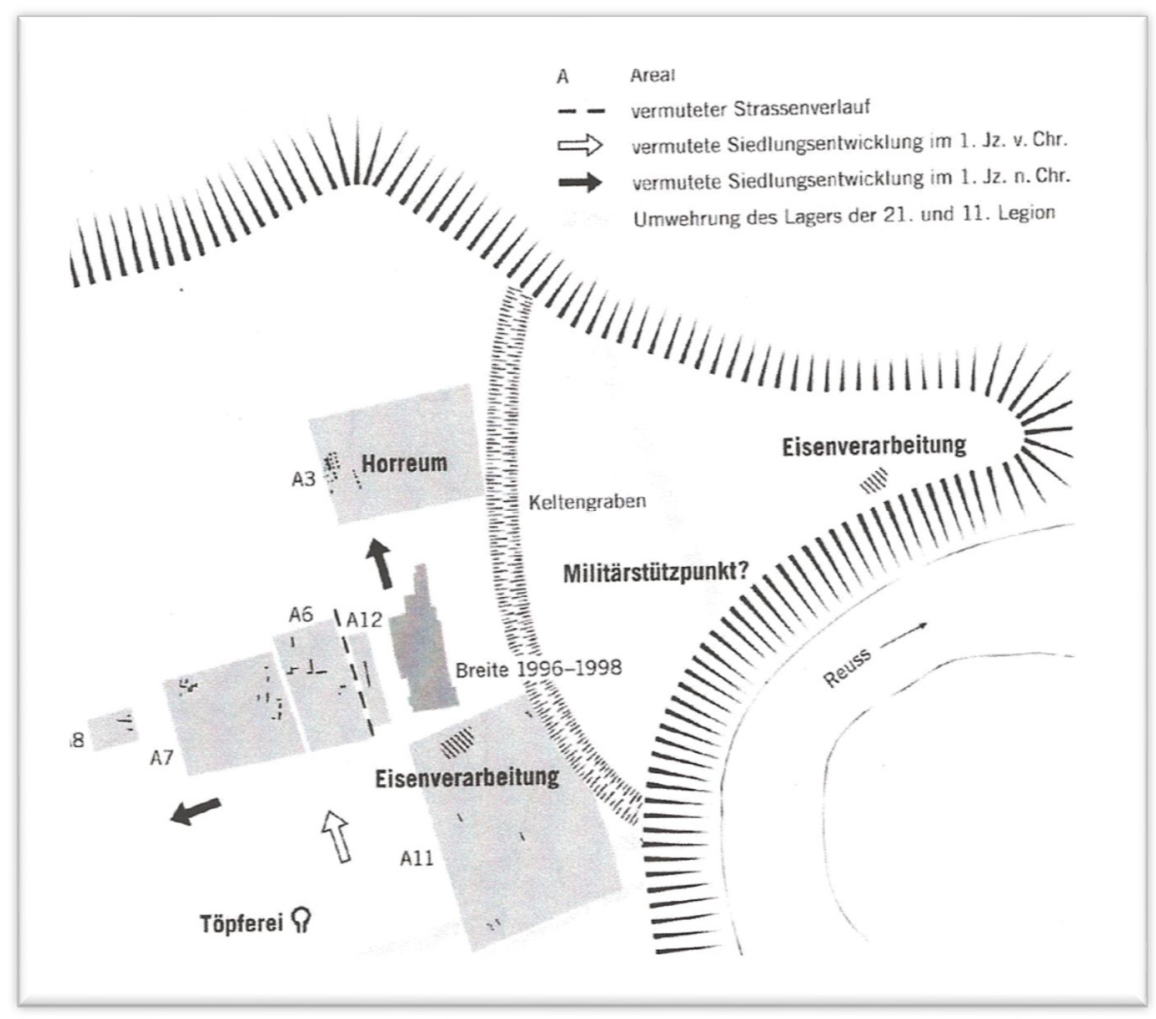

Abb. 10 Windisch-Breite: Einheimische Siedlung und Militärstützpunkt (?) (nach Hagendorn (Hg.) 2003 Abb. 69) 
Frankfurter elektronische Rundschau zur Altertumskunde 34 (2017)

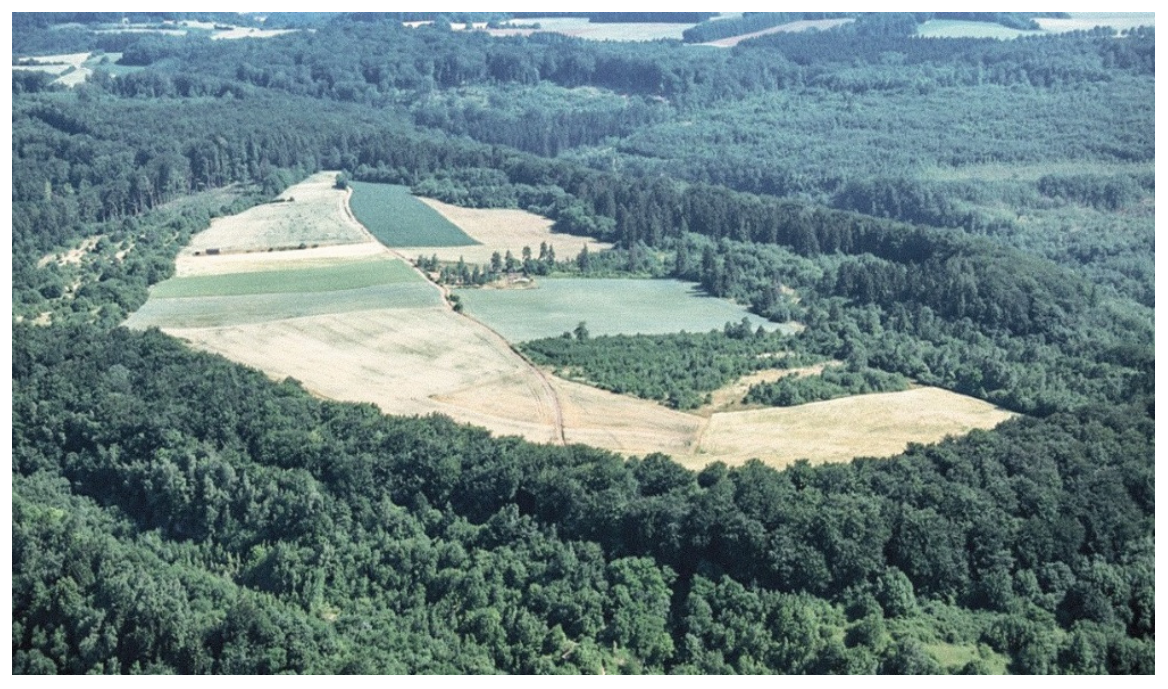

Abb. 11a Titelberg (L) - Luftaufnahme

(C) Minett Park [L])

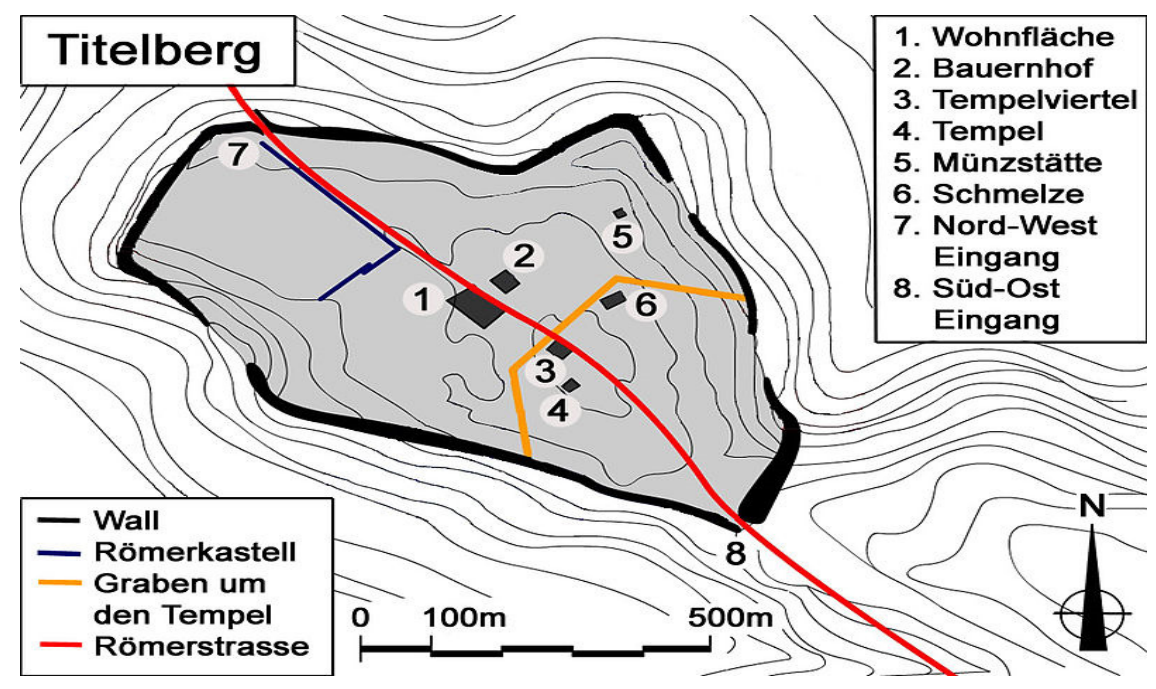

Abb. 11b Titelberg (L) - Plan des Oppidum

(C) Jim Hawk - CC BY-SA 3.0) 
Frankfurter elektronische Rundschau zur Altertumskunde 34 (2017)

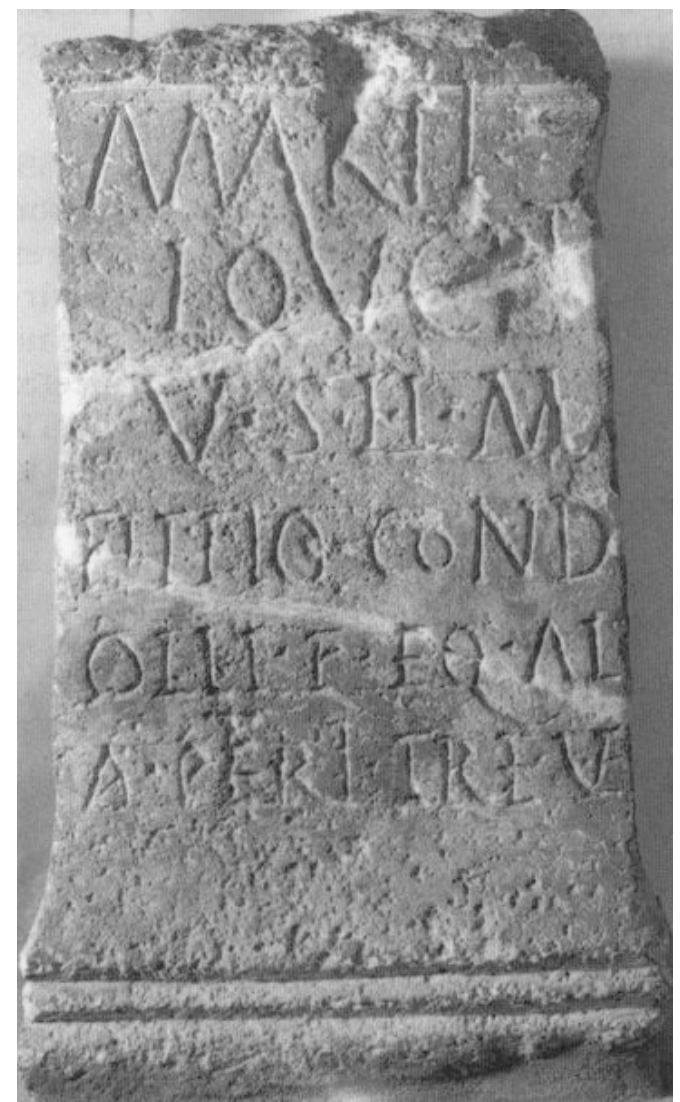

Abb. 12 Argentorate/Straßburg - Grabstein eines Reiters des ala Petriana (CIL XIII - Photodatei Flensburg/Trier)

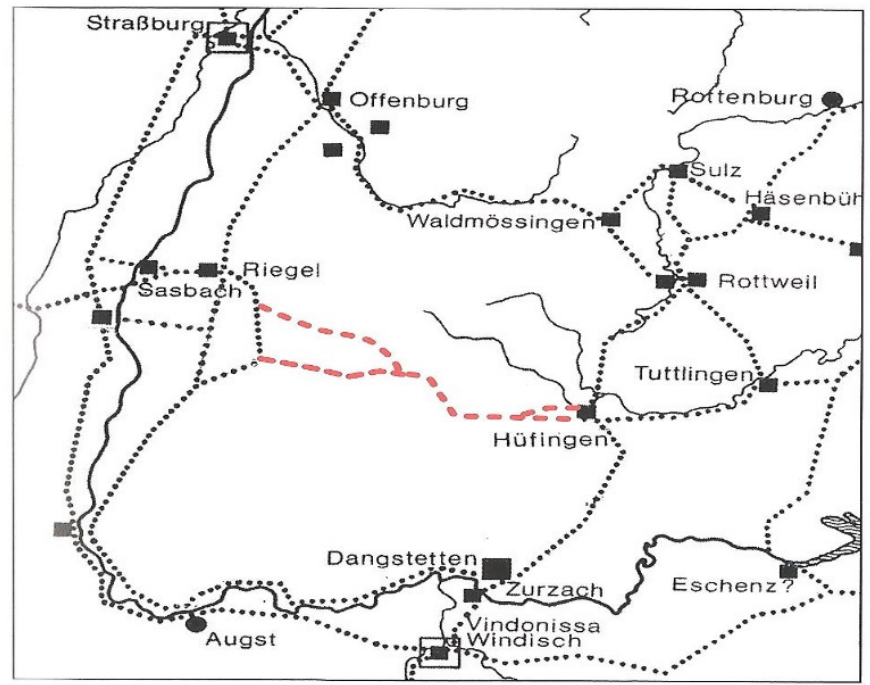

Abb. 13 Frühe römische Truppenlager und Straßen vom Oberrhein zur oberen Donau (nach Fingerlin 2006, Abb. 2) 
Frankfurter elektronische Rundschau zur Altertumskunde 34 (2017)

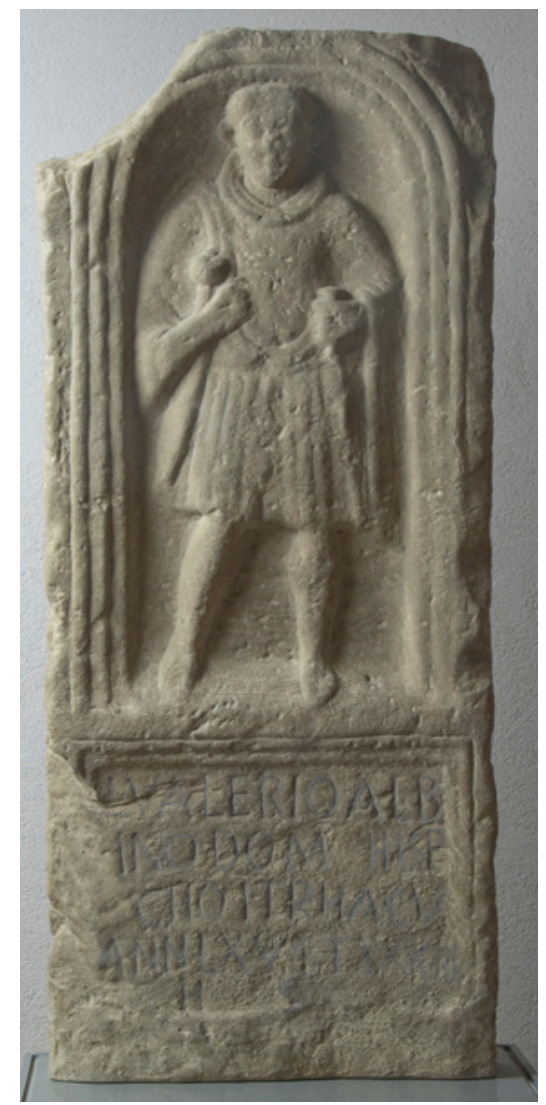

Abb. 14 Offenburg - Grabstein eines centurio der cohors I Thracum (CIL XIII Photodatei Flensburg/Trier)

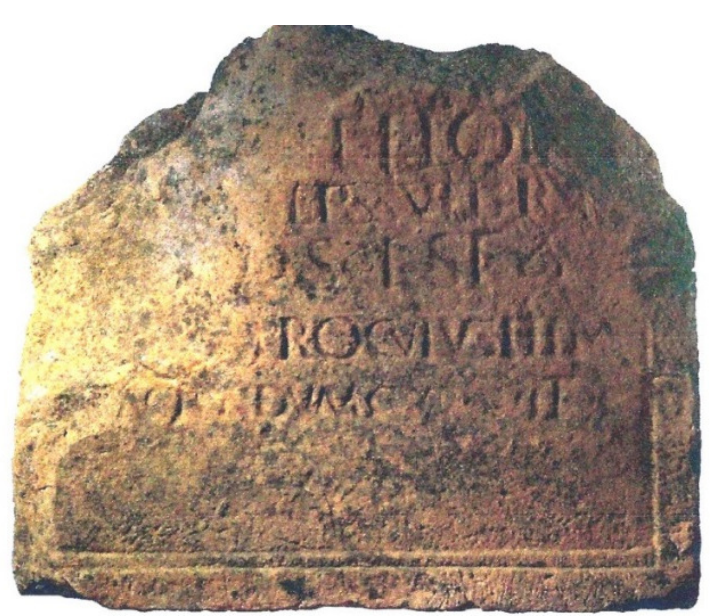

Abb. 15 Offenburg-Buhl (Ortenaukreis) - Grabstein eines princeps Sueborum (nach Arch. Korrbl. 46, 2016, Abb.2 [J. Lauber]) 